\title{
Los bienes comunales y la necesidad de justa colaboración
}

(Relación histórico-critica tomada de las lecciones pronunciadas por el Ingeniero de Montes D. Antonio Lleo, en el Instituto de Estudios de Administración Local, a los alumnos del Secretariado Local (2. ${ }^{a}$ Categoría) los días ro y i 7 de abril de 1945).

Había transcurrido un considerable ciclo de cambios cosmológicos, propiciándose la conjugac:ón de elementos que integraban los primitivos gérmenes. $\mathrm{Y}$ pasó otra larga etapa en que esos seres fueron evolucionando.

Desde los rasgos más remotos de imaginación artística, se alegorizan en el mito las divensas creencias acerca de los designios y motivos del ser, en sus múltiples aspectos y vicisitudies...

El arte del mito es la metáfora de la hipótesis; pero también puede ser la alegoría de la real:dad... En todos los pueblos, de un modo u otro interpretado, desde las primeras deducciones de la vida plural, se ofrecen a la libertad dos conocimientos bien fundados. No por elemental, habremos de omitir en esto la mención del Arbol de la Ciencia del Bien y del Mal, en cuyas hojas se irisaba la maravillosa luz del eterno día; pero en uno de los frutos de tal plenitud se ocultaba el áspid que había de cantivar la voluntad del hombre, derivando las generaciones por el cauce predominante de mal, iniquidad, expiación y complicados o superfluos trabajos. Esclavo ya de bajas pasiones; proscritos del Paraíso, Adán y Eva, habían no obstante de transmitir ambas propensiones que en el Arbol se integraban sin confundirse jamás. $\mathrm{Y}$ así las dos herencias: la de Caín, maldito, y la de Abel, que mucho más tarde había de llegar a un realismo sublime.

Los hombres primitivos, librados a su suerte, encuadrados en la ley de la evolución, guiados por su instinto y por los lentos avances de su razón, tuvieron, según el medio donde se hallasen, que ir roturando, por asi decirlo, los arcanos que a su paso se les oponían. Y el hombre, apri- 
sionado en la selva virgen, descubrió el fuego, y con la tea encendida, único modo de abrirse paso en medio de aquella cernada espesura, empezó a dominar a la Naturaleza. Entre tanta dificultad, no todo le era adverso, sin embargo; sus condiciones eran aptas para resistir a las inclemencias y luchar con las fieras, con mayor éxito, y beneficio más tardé, a medida que se forman núcleos de población. Pero su actividad, desde los primeros allcances, es de lucha obligaida para progresar, acuciado por las más simples neces:dades.

Anrasado alyún espacio por medio del fuego, brotó la hierba, y observaba que unos animales acudian a comer de ella. Bien pudo esto sugerirle el primer modo productor para su sustento, cultivando las plantas y los fragantes frutos, cuyas cualidades iba conociendo. $Y$ surgió la Agricultura.

Textos sagrados, sabiamente refieren que el hombre fué primero agricultor y luego ganadero, y res lógioo que así haya sido, porque era lo inmediato, y es más fácil dominar las plantas que capturar y domestoar animales.

Esta prioridad en la producción, se ha demostrado además documentalmente por investigadores alomanes. $\mathrm{Y}$ se ha comprobado, viendo en apartados sectores de bosques suramericanos, que sus moradores realizan un cultivo agrícola, pero no conocon el pecuario o ganadero; siendo tan sólo una agricultura de azadia, no de esteva, la cual es posterior resultadio de la conjunc:ón de actividad peouaria o ganadera y agraria.

En su afán de ampliar los medios de atender a sus neoesidadles, trató de apresar las especies acuáticas, terrestres y aéneas, inventando los ardides, ligas e instrumentos, el arte de cazar; transición por la cual había de pasar a ser ganadero y guerrero, repercutiendo en esto último aquel mot.vo de ceder a su egoísmo, a su ineptitud ancestral para guardar la paz ofrecida por el fruto del Bien. Porque envenenado por su contrario; cediendo a la vanidadi y a la envidia desde sus primeras relaciones seudasociales; cediendo el varón a ese espíritu de jactancia y prepotencia, exhibiéndose ante la mujer y con ésta ante otros, habia de complicarse la vida a través de sanguinaria historia, sin descifrar por mucho tiempo, a pesar de los siglos y de los más inequívocos ejemplos, el sentido espiritual que deberá emprender, en que consistirá su noble ventaja: m:entras no la conoce, el hombre es inútil para suscitar la armonía humana; seudosabio para mantener una perenne discordia.

El ejercicio de la caza y aplicaciones al consumo, anteror a la captura y domesticación de animales destinados a la labor agrícola; la caza 
y la ganadería requerían todas ias condiciones viriies. La mujer, esclava de la especie, ten:endo que atender a la prole, no podía cazar; pero sí espurgar las malas hierbas, recoger las semillas, ayudar a sembrarlas, cosechar las gramíneas, y se realiza ese gran paso de la Humanidad, la incipiente producción cerealista, descubriendo sucesivamente los rudimentarios procesos de molienda, amasado, amalgama, cacción $y$, en definitiva, el pan, ese milagro de la alimentación, manjar sin rival, símbolo de la justicia distributiva de Dios, alimento que $\mathrm{El}$ da para todos los hombres.

La mujer podía atender a la prole y cuidar la tierra; la agricultura fué impulsada por la mujer. Pero ya en avanoe la ganadería, surgieron de vez en cuando pugnas. El mito de la lucha entre Caín (agricultor) y Abel (ganadero). La agricultura busca la satisfacción d'e las necesidades individuales de la familia del cultivador. La ganadería necesita la colaboración y defensa colectiva. De ahí se deduce el difenente carácter de la agricultura y de la ganadería; individualista y oolectivista, respectivamente.

La falta de comprensión en esas desavenencias ya radicaba en cerrarse cadla cual en su punto de egoísmo intolerante, sin colaborar toda persona hábil en diversas actividades útilles, en el Bien; sin iniciarse aún desde entonces una equidad mundial entre los aspeotos privado y públioo del interés humano.

No son incompatibles la ganadería y la agricultura; la colisión sólo proviene de inoomprensión o de especulación.

El modo primigenio de abrirse paso en la selva virgen; ta tea encendida, fué puesta desdie el más antiguo culto griego como atributo de Déméter, cantada por Homero y por Hesiodo.

$\mathrm{Y}$ en el simbolismo romano es venerada oon el nombre de Ceres. Diversas figuras ha ten:do esa deidad mitológica, propiciadora de los frutos de la tierra, en especial el trigo, adornada de otros diversos atributos, entre ellos las espigas, de las que suele llevar una corona ciñendo sus cabellos.

El hombre, para capturar algumas die las especies terrestres, tuvo que valerse de encierros y trampas, en las que fácilmente caen las animales jóvenes, mas no así todos los adiultos, atraídos por algún alimento.

La ayruda espontánea de los seres comienza en un mexo de desplazamiento, más ullteriormente en un punto de fecundación y en el olaustro materno. Desde los expresados modos de abrirse paso la iniciativa individual, pronto tuvo que ser ayudada, a cuya rudimentaria organ:- 
zación colectiva y jerarquía de esfuerzos sucede la formación de los primeros prados. Y sugiriendo éstos, la agricultura; y la caza y sus cuidados, la ganadería, y ésta la necesidad de anchura (en la selva, o en espacios aptos de natural), comienza por familias sedentarias principalmente, la apropiación, la ocupación. Cada tribu considera como suyo el territor:o que ooupa, y sólo sus familias aprovechan en común los pastos con sus ganados. Se configuran estas manoomunidades embriorarias, de reducido interés común, espontáneo, de bienes comunales. Pero entre las miembros y entre las familias la semilla de la discordia fructifica $y$ se sucede a través de las generaciones.

En particular, el aprovechamiento pecuario requirió la existencia de mancomunidad. La fuerza de las cosas estableció en el territorio común, desde aquellos momentos de incipiente actividad agropecuaria, la distinción de las tierras laborables y de los bosques y prados. La agriculura se cincunscribia a extensiones menones que las d'e su rival, aunque ampliándose ésta en casos sedentarios.

La ganadería es colect:vista; lo es, por consiguiente, el aprovechamiento de prados, bosques y montes, por lo regular. Para obtener benefic:o de éstos, tienen que pertenecer a la comunidad.

Según Aristóteles ("Política", libro II), las tierras arables se dividian y sorteaban anualmente entre las familias, al efecto de cultivo y con la obl:gación de situar las cosechas en acervo común, para repartirlas luego según las necesidades de cada familia. A). Eran, pues, tierras comunales de cultivo agrícola.

Van refiriéndose prados y tienras arables comunales y bosques del mismo carácter, en todo lo cual se manifiesta, mayor o menor, la necesidad natural de colaboración. En todo tiempo y pais se considera lóg:co que cada pueblo tenga bienes de carácter comunal.

En iberos y celtas, se repiten más tarde aquellos sorteos. En los Higlands, de Escocia, y en Irlanda. Pero por diversos factores, cuyo análisis prolongaria este trabajo, el aprovechamiento en común de las "tierras arables", se desintegró hasta transformarse en propiedad individual. El ganado, por rarísima excepc:ón, era del común. No obstante esa clase de bienes comunales, $y$ otros que indicaremos, la propiedad individual era de origen o resultado por ocupación, por botín y por despojo. $\mathrm{Y}$ siguen las guerras, con nuevos aportes de discordia. $\mathrm{Y}$ así en iberos y celtas. Silio Itálico refiere el carácter bélico de los españoles, como guión indígena. 
La vida era sedentaria, mientras la tierra próxima a la choza proporcionaba medios para alimentar el ganado; ouando se agotaba por varias razones, se trasladaban a otros parajes. Estos éxodos eran otra causa más de colisiones. Se produjeron etapas de trashumancia, y se imicia la agricultura en las tierras inclinadas.

Ocurren por egoismo los primeros destrozos de arbolado en esas tieTras; que si en paises llanos y húmedos, la desaparición del monte no es muy sensible, es incalificable que ocurra en laderas y montes altos, domide el árbol es sostén de la tierra y defensa del valle.

A causa de esas luohas se buscaron lugares más inaccesibles para la defensa, uno de los orígenes de la fortificación. Y de la mala distributción, consiguiente a todo plan de ocupación arbitraria, desnaturalizado aquel sesgo de aprovechamiento común, ocurre el encontrarse unos en rediucidos espacios y con población en aumento. ( $Y$ surge $o$ se repite la tragedia del hombre sin tierra.)

Entonces piensan y realizan por vez primera el estenoolamiento para forzar la produoción algunos de los que poseían terreno reducido; aplicación de la ganadería a la tierra, sugerencia del paso de la azada a la esteva. Parece ser que esto empezó en España desde Africa, y en Oriente hasta el Danubio. La alimentac:ón de simples raices se amplía en la de otros vegetales más sustanciosos y se nutte mejor el ganado destinadio al indicado fin.

B) La antigüedad de montes comunales y de otros bienes adjetiva. dos se origina, por lo regular, de verse los individuos obligados a la cooperación, y data en los distintos países desdie que adquieren volumen de importancia las explotaciones forestal y agropecuaria, y en todo tiempo y pais hay montes comunales, terras de cultivo y prados en común.

En el año 98 de nuestra era ya lexistía la división estre propios y comunales. Así, en una lámina de bronce encontrada en Plasenoia en 1747, está representado que el emperador Trajano otorga cesión de unos terrenos, y al describir sus límites dice "que lindan en su mayor parte con tierras del común".

Es en el Derecho romano donde se configura propiamente una reglamentación de la agricultura, ganadería y montes; pero también la diversidad y profusión legislativa. Sagazmente distingue bienes de los. Dioses y bienes de los hombres. Entre los primeros, algunos montes: los quie están junito a los nacimientos y en las riberas de los ríos, que defienden de impurezas las aguas. Son selvas "sagraidas", ouyas leñas sólo se extraen para las hogueras de los sacrificios, y hierbas para alimentar 
las reses destinadas a esas ofrendas. Interés nacional, diriamos hoy, en cuanto a la defensa purificadora de las aguas.

Los bienes de los hombres se subdividían en privados y públicos. Pprivados, todos los que son objeto de enajenación y de comencio. Públicos, los destinados al aprovechamiento de la oolectividad, directo e indirecto (nuevo precedente de los comunailes en el primer caso: los que el conquistador asignaba, por ser terrenos ricos, para ese destino).

Los comunales consistían prados (dehesas boyalles), bosques y montes. Los compascuus, comprendian bienes comunales y de propios. Otros bienes se reservaban para ulterior finalidad del Imperio. Eran del Estado, para construociones navales y realizaciones que excedían de la posib:lidad local. Se llamaban exceptus (Los reservados dell Municipio se llaman desde antiguo "pagos privativas").

San Isidoro menciona los compascuus ager (selvas y prados comunes), de los consortes godos y los hóspites hispano-romanos.

El Fuero Juzgo ordenaba que "el uso de las hierbas, no cerradas, sea común a vencedores y vencidos". "Con la caída del Imperio romano y la invasión de los bárbanos, se subvierten en particullar las formas de dominio.

Mury agrícolas eran los suevos. Entre éstos parece ser que no existía la propiedad privada de la tienra, y el cultivo se practicaba labrando en distinta hoja cada año (César. "De Bello Gallico", IV, I), "año y vez" para alternar y barbechar. El terreno pertenecía a la civitas; los magistrados hacian ell reparto de la cosecha. A su vez, Tácito y Orosio refieren la indicada forma: año de cosecha y otro año de descamiso al terreno, y alternativa de oultivo cadla hoja. Los sulevos, all decir de dichos historiadores, "convirtieron sus espadas en arados".

En los primeros t:empos de los godos, la propiedad comunal tuvo gran extensión, y siempre, entre ellos, vendadera importancia agrícola. Probablemente de origen común com las gantios de Escamdinavia, tenían tierras del común, y otras privadas, así en España. Tiene lugar un cambio de dominio, al entrar los godos en nuestra Patria. Las propiedades en cultivo, gran parte fueron dejadas en posesión de los agrioultores. Respetanon los bienes de los Municipios; se apoderaron de los del Estado (exceptus) y se los distribuyeron los feuddales, como galardón. Así pasaron al señorío feudal los bienes públicos exceptuados, y los de uso público, viniendo, pues, a ser privados, sobre cuyo uso exigían aquellos tributos de tránsito, "pontazgo", "pontazgo", etc.

Se arrogan la soberanía absoluta, unida al atributo de ser "dueños de 
vidas y haciendas". Esto fué más acentuado aún en Europa Central; en España esturo frenado por los árabes.

A través de la Reconquista, lógicamente los ooupantes de los sitios de la misma tenían prerrogativas, y por el interés de territor:o fueron unos paladines de su defensa. Para lograr ese enraizamiento y temple heroico para mantenerlo y ensancharlos, se caracteriza aquella época, en el aspecto legislativo, por las Cartas pueblas, texto jurídico-político de facultades otorgadas por el rey a las representaciones de las localidades para poblar y repoblar, en acepción demográfica, y las Cartas foreras, para que cada pueblo se dictase su propia constitución y organización según sus usos y costumbres.

Caracteres de esta legislación: democrático y respetuoso con el pueblo, otorgándole normas y atribuciones para desenvolverse en interés general. Las t:erras concedidas tenían que ser utilizadas en común. Ello se preceptúa en la generalidad de los Fueras (de Soria, Salamanca, Cáceres, Cuenca, etc.) y se recoge en el Código de las Siete Pantidas, con notable alcance, consignándose la atribución real de otorgar a los Ayumtamientos diversas prerrogativas (en materia de caza, forestal, etc.).

La comunidad en el aprovechamiento surge de la ya indicada necesidad de unir esfuerzos. Esto es inconcuso. Se dice por algunos historiadores que la comunidad surge en el aprovechamiento de pastos, $y$, por consiguiente, un derecho al usufructo mancomunado y en proporoión al ganado de cada uno, y la propiedad individual o familiar del ganado, vendadera propiedad particular que por rarísima excepción es del común.

Sea de ello lo que quiera, pues no hemos de extendernos en él presente trabajo, hemos, sí, de insistir en que esos bienes comunales vienen siendo una necesidad del oonjunto social, contiguo, o continuo, en una demarcación territorial.

Consideraciones de similitud con personas individuales, en el concepto hasta ahora de prop:edad, exigen para los Municipios como persoma jurídica que tengan además bienes propios, o patrimonio para la realización ide servicios municipales, consistiendo, como sabemos, en bienes muebles y valores e inmuebles, tanto rústicos como edificios e instalaciones. En fin, otros bienes municipales son los llamados de uso público, variables al ritmo de los adelantos realizados, en vialidad, higiene, mejoramiento, instruoción, suministros, ornato, etc., etc., de las poblaciones.

En el mencionado Código de las Siete Partidas se definen esas pro 
piedades perdurables, esos conceptos al del pueblo, diciendo son bienes de propios los "campos e viñas e huertos e olivares e otras heredades e ganados e siervos, e otros semejantes, que dan fruto de sí o renta, que pueden haber las cibdades e las villas" - $\mathrm{y}$ los comunales - "E como quiera que sean comunalmente de todos los moradores de cibdad e de la villa, non puede cada por si, usar de tales. Mas los frutos e las rentas, deben ser metidos en precomunal, cuyas fueren las cosas; asi como los muros, puentes, fortalezas, castillos o cosas semejantes a estos que pertenezcan al precomún". (Partida III, Título XXVIII, Ley VI). "Pueblo, tanto quiere decir como Ayuntamiento de gentes que viven en común (Partida I, Título II, Ley V). "Cuidan algunos que el pueblo es llamado la gente menuda, asi como menestrales e iabradores. Esto non es así, sino ayuntamiento de todos los homes comunalmene; de los mayores, e de los medianos, e de los menores, ca todos son menester, e non se puede excusar, porque se han de ayudar unos a otros, porque puedan bien vivir e ser guardados" (Partida II, Título X, Ley I).

Para que la humanidadi se oriente hacia un nivel bastante de equidad, es indispensable partir de una base sin dominio directo de nadie, y en la que toda persona útil colabore. En distintos momentos y en países distintos, se repite la providencial sugerencia de lo que acabamos de expresar. $Y$ la necesidad de los bienes comunalles para los Municipios es una advertencia constante de esa verdad, de cuyos bienes depende la satisfacción de sus necesidades y es el menor precedente que puede tener el indicado anhelo.

Los reyes de nuestras mejores etapeas, legislarion ondenando la restitución de bienes propios y comunales a los pueblos; y si por lamentable excepción las leyes desamortizadoras, en gran parte, interrumpieron esa tradición con resultados perdurables, esperamos emprender, o que otros tenigan el suficiente apoyo para acometer un plan de reivindicación y de mayor orientación hacia esa base de íntegro y no sólo geineral interés en un elevado sentido.

Madrid, ro de mayo de 1945.

Los alumnos del Secretariado local de segunda categoría del Instituto de Estudios de Administración Local. 
NOMENCLATOR de las Secretarias de Administración Local de segunda categoria, segrin el Censo de la población de España, en $3 I$ de diciembre de 1940.

(Continuación)

\begin{tabular}{|c|c|c|c|c|c|}
\hline MUNICIPIOS & PARTIDO JUDICIAL & $\begin{array}{c}\text { Población } \\
\text { de } \\
\text { derecho }\end{array}$ & $\begin{array}{c}\text { Sueido minimo } \\
\text { que le } \\
\text { corresponde }\end{array}$ & Presupuesto en 1943 & OBSERVICIOMES \\
\hline 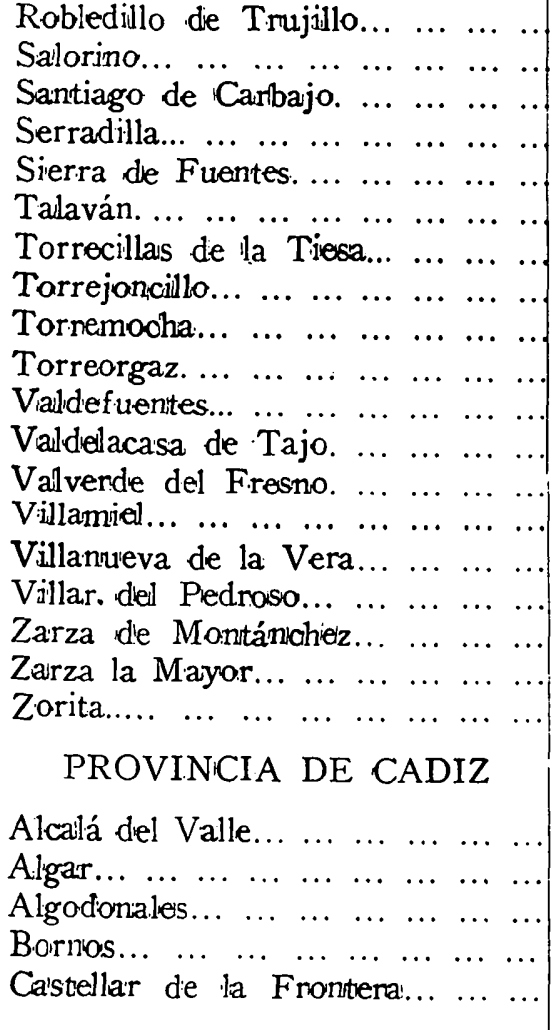 & 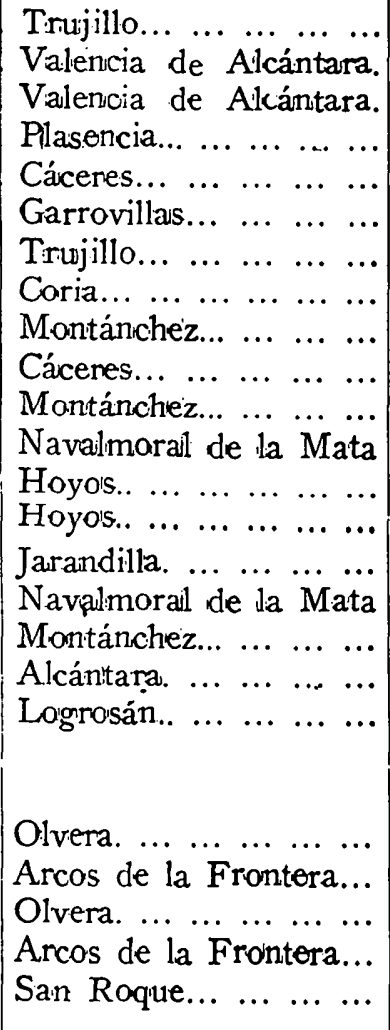 & $\begin{array}{l}2.099 \\
2.624 \\
2.648 \\
4.385 \\
2.799 \\
3.029 \\
2.462 \\
5.149 \\
2.951 \\
2.128 \\
2.919 \\
2.365 \\
3.858 \\
2.215 \\
3.403 \\
2.364 \\
2.008 \\
4.407 \\
6.098\end{array}$ & $\begin{array}{l}5 \cdot 500 \\
5 \cdot 500 \\
5 \cdot 500 \\
6.000 \\
5 \cdot 500 \\
5.500 \\
5 \cdot 500 \\
6.000 \\
5 \cdot 500 \\
5 \cdot 500 \\
5.500 \\
5.500 \\
5.500 \\
5.500 \\
5.500 \\
5 \cdot 500 \\
5.500 \\
6.000 \\
7.000\end{array}$ & $\begin{array}{r}53 \cdot 621,46 \\
76.670,96 \\
76.396,03 \\
197 \cdot 743,97 \\
98.200,00 \\
155 \cdot 323,99 \\
85 \cdot 940,35 \\
290.682,05 \\
185 \cdot 350,43 \\
65.662,07 \\
72.401,60 \\
90.491,79 \\
111.275,94 \\
56.276,83 \\
124.867,80 \\
85.291,72 \\
50.278,84 \\
132.951 .37 \\
238.105,53\end{array}$ & • \\
\hline
\end{tabular}




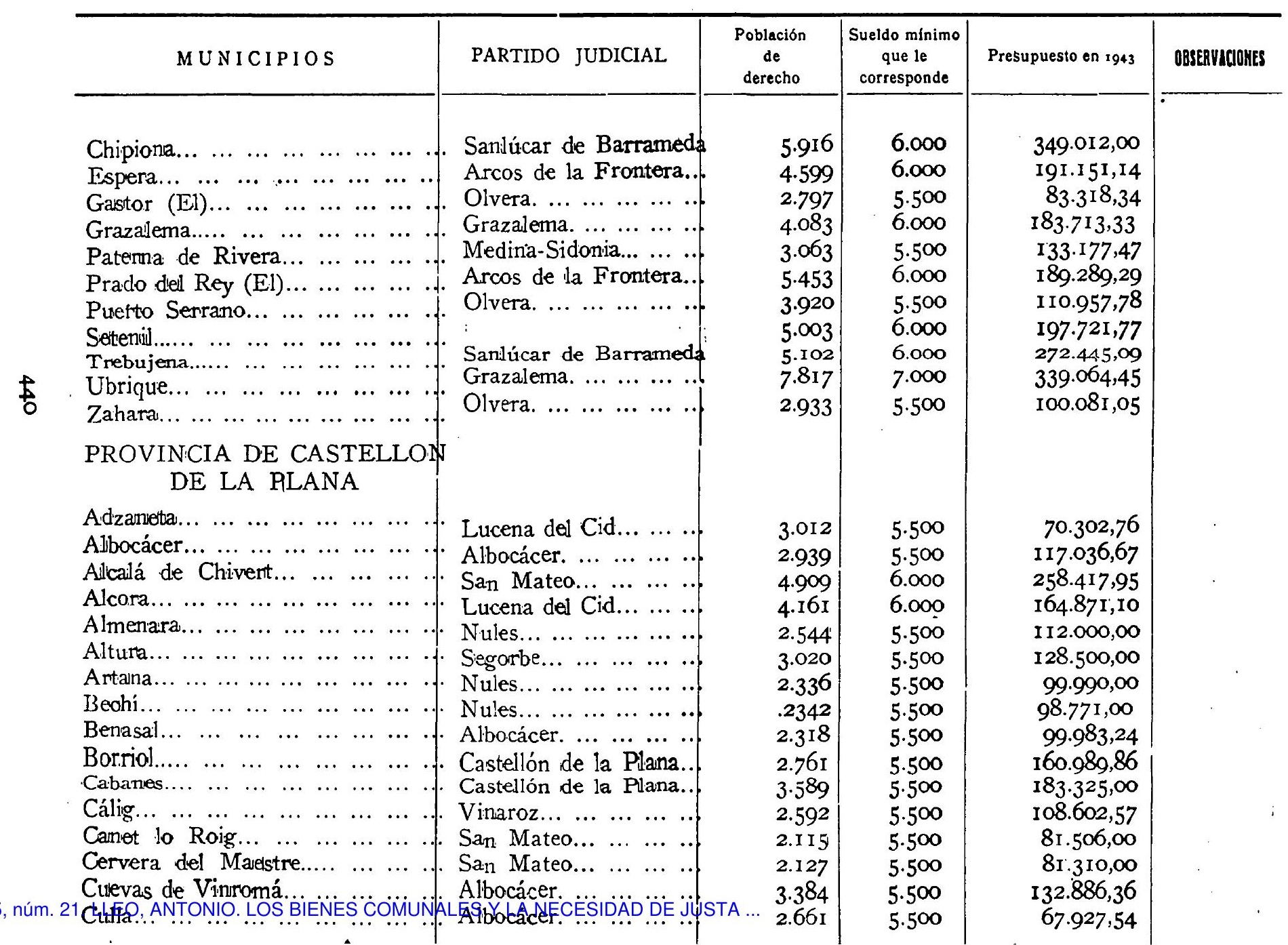


Chert..

San Mateo . .

Lucena del $\mathrm{Cid} \ldots \ldots \ldots$

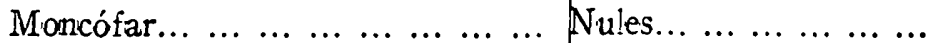

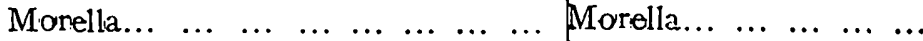

5.216

Nules... . .

6.545

Onda.

Nules... ...........

$7.67 \mathrm{I}^{\prime}$

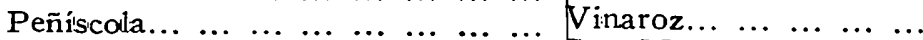

3.098

San Mateo....

\begin{tabular}{llllllll} 
Segorbe.... & $\ldots$ & $\ldots$ & $\ldots$ & $\ldots$ & $\ldots$ & $\ldots$ & $\ldots$ \\
\hline
\end{tabular}

San Mateo... ... ......

$3.17 I$

6.717

Castellón de la Plana...

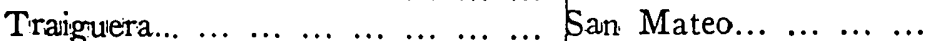

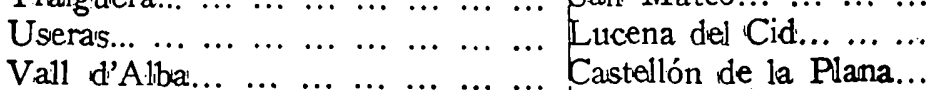

2.586

2.943

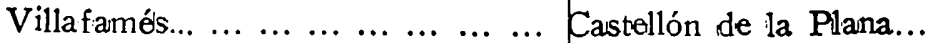

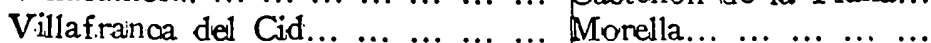

3.850

$3.63 \mathrm{I}$

Villahermosa diel Río... ... ... ... Lucena del Cid... ... ...

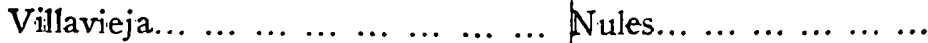

2.499

2.772

Vistabella del Maestrazgo... ....... Lucena del Cid.........

PROVINCIA DE CIUDAD REAL

Abenójar..

Almodóvar del Campo.

Agudo...

Almadén... ...........

Alamillo...

Almadén... ............

Abadalejo

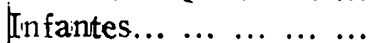

Alcolea de Calatrava...

$\begin{array}{lllllllll}\text { Alcubillas... } & \ldots & \ldots & \ldots & \ldots & \ldots & \ldots & \ldots\end{array}$

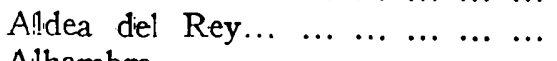

Piedrabuena... .........

Infantes... ... ... ... ...

A.rgamasilla de Alba..

I $81.938,46$ 


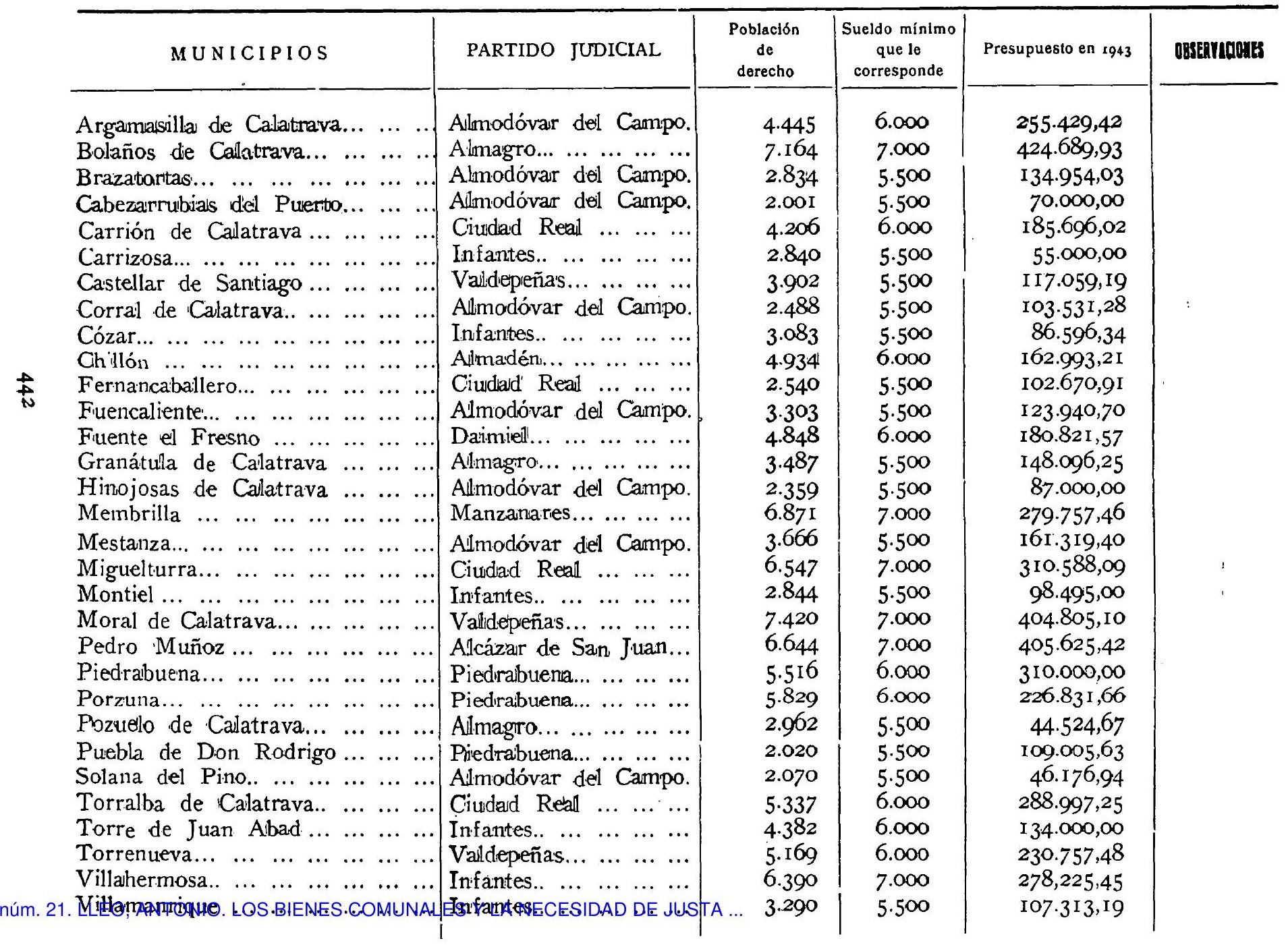


REVL-1945, núm. 21.Milleamayyortorde. Colabramas. COMUNA

Villanueva de la Fuente... ... ...

V.llarta de San Juan ... ... ... ...

$V$ iso del Marqués... $\ldots \ldots \ldots \ldots$

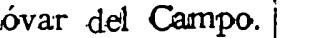

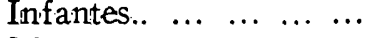

$4.56 \mathrm{I}$

Manzanares... ... ......

Valldepeñas... $\ldots \ldots \ldots$

\section{PROVIINICIA DE ICORIDOBA}

$\begin{array}{lllllllll}\text { Adamuz } . . & \ldots & \ldots & \ldots & \ldots & \ldots & \ldots & \ldots\end{array}$

Alcaracejos ...

A.lmedinilla ...

Almodóvar del Río... ... ... ... ...

$\begin{array}{lllllllll}\text { Añora.. } & \ldots & \ldots & \ldots & \ldots & \ldots & \ldots & \ldots & \ldots\end{array}$

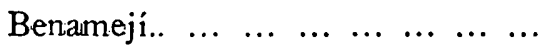

Cañete de las Torres ... $\ldots . . . . .$.

$\begin{array}{llllllll}\text { Carcabuey } & \ldots & \ldots & \ldots & \ldots & \ldots & \ldots & \ldots\end{array}$

$\begin{array}{lllllllll}\text { Cardeña... } & \ldots & \ldots & \ldots & \ldots & \ldots & \ldots & \ldots\end{array}$

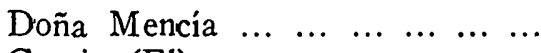

Cat pio (El)...

$\begin{array}{lllllll}\text { Dos-Torreis... } & \ldots & \ldots & \ldots & \ldots & \ldots & \ldots\end{array}$

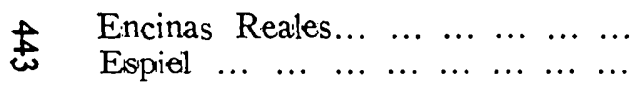

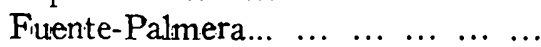

$\begin{array}{lllllll}\text { Fuente-Tójar } & \ldots & \ldots & \ldots & \ldots & \ldots & \ldots \\ \end{array}$

\begin{tabular}{lllllll} 
Guadallcázar... & $\ldots$ & $\ldots$ & $\ldots$ & $\ldots$ & $\ldots$ & $\ldots$ \\
\hline
\end{tabular}

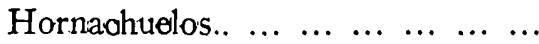

Montalibán de Cóndoba... ... ... ...

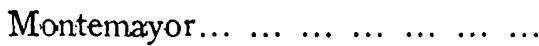

$\begin{array}{lllllll}\text { Monturque } \ldots & \ldots & \ldots & \ldots & \ldots & \ldots & \ldots\end{array}$

$\begin{array}{llllllll}\text { Moriles } \ldots & \ldots & \ldots & \ldots & \ldots & \ldots & \ldots & \ldots\end{array}$

$\begin{array}{llllll}\text { Nueva-Carteya... } & \ldots & \ldots & \ldots & \ldots & \ldots\end{array}$

$\begin{array}{lllllllll}\text { Obejo.. } & \ldots & \ldots & \ldots & \ldots & \ldots & \ldots & \ldots & \ldots\end{array}$

$\begin{array}{lllllll}\text { Palencianal ... } & \ldots & \ldots & \ldots & \ldots & \ldots & \ldots\end{array}$

$\begin{array}{lllllll}\text { Pedro Abad... } & \ldots & \ldots & \ldots & \ldots & \ldots & \ldots\end{array}$

Montoro... $\ldots \ldots \ldots \ldots$

Pozoblanico...

Priega de Córdoba..

Posaidas... ... ... ... ...

Pozoblanco... $\ldots \ldots$...

Rute... ... ... .......

Buijalance

Priego de Córdoba.. ...

Montoro... ... ... ... ...

$\begin{array}{llllll}\text { Cabra } & \ldots & \ldots & \ldots & \ldots & \ldots\end{array}$

Bujallanioe $\ldots \ldots \ldots$

Pozoblanco... $\quad \ldots \quad \ldots .$.

Lucena ...

Fuente Ovejuna ... ...

Posadais... ...

Priega de Córdoba..

$\begin{array}{lllll}\text { Posadas... } & . . & \ldots & \ldots & \ldots\end{array}$

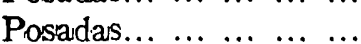

La Rambla... ... ... ...

Lia Rambla... ... ... ...

$\begin{array}{lllll}\text { Agguillar... } & . . & \ldots & \ldots & \ldots\end{array}$

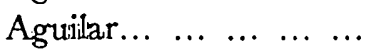

Cabra ...

$\begin{array}{lllll}\text { Córdoba.. } & \ldots & \ldots & \ldots & \ldots\end{array}$

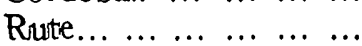

Bujallanios ... $\ldots \ldots \ldots$ 


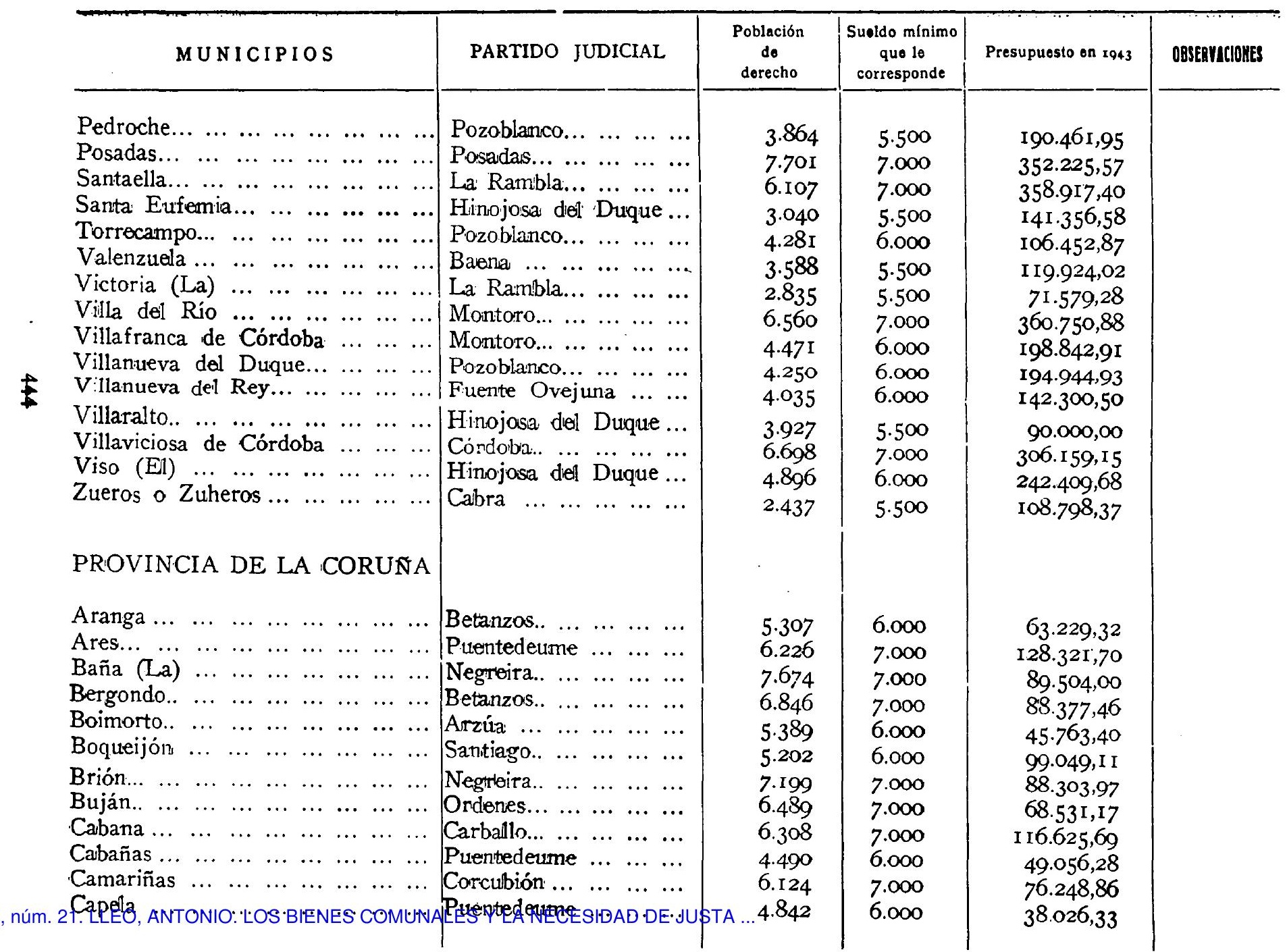


REVL-1945, núm. 21 CLEEO ANTONIO. LOS BIENES COMUNAL

Cée

S Y COR UnaCESIDAD DE JUSTA ....

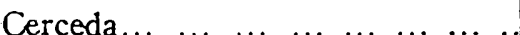

Corcubión ....

Ordenes... $\ldots \ldots \ldots \ldots$

7.613

\begin{tabular}{llllllll} 
Cerdido... & $\ldots$ & $\ldots$ & $\ldots$ & $\ldots$ & $\ldots$ & $\ldots$ &.. \\
\hline
\end{tabular}

Ort:gueira ...

3.709

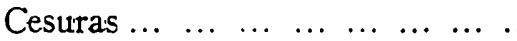

Betanzos.. ..........

$6.55^{\circ}$

$\begin{array}{lllllllll}\text { Coirós.. } & \ldots & \ldots & \ldots & \ldots & \ldots & \ldots & \ldots & \end{array}$

Betanzos.. ... $\ldots \ldots \ldots$

$\begin{array}{llllllllll}\text { Curtis... } & \ldots & \ldots & \ldots & \ldots & \ldots & \ldots & \ldots & \ldots\end{array}$

$\begin{array}{lllllllll}\text { Dodro.. } & \ldots & \ldots & \ldots & \ldots & \ldots & \ldots & \ldots & \end{array}$

$\begin{array}{lllllll}\text { Dumbría ... } & \ldots & \ldots & \ldots & \ldots & \ldots & \ldots\end{array}$.

$\begin{array}{llllll}\text { Arzúa } & \ldots & \ldots & \ldots & \ldots & \ldots\end{array}$

Padrón...

\begin{tabular}{llllllll} 
Enfesta & $\ldots$ & $\ldots$ & $\ldots$ & $\ldots$ & $\ldots$ & $\ldots$ & $\ldots$ \\
\hline
\end{tabular}

$\begin{array}{llllllll}\text { Finisterre } & \ldots & \ldots & \ldots & \ldots & \ldots & \ldots & . .\end{array}$

\begin{tabular}{lllllllll} 
Frades & $\ldots$ & $\ldots$ & $\ldots$ & $\ldots$ & $\ldots$ & $\ldots$ & $\ldots$ &.. \\
\hline
\end{tabular}

\begin{tabular}{lllllllll}
$\operatorname{Irijoa} \ldots$ & $\ldots$ & $\ldots$ & $\ldots$ & $\ldots$ & $\ldots$ & $\ldots$ & $\ldots$ & $\ldots$ \\
\hline
\end{tabular}

$\begin{array}{lllllllll}\text { Lage } \ldots & \ldots & \ldots & \ldots & \ldots & \ldots & \ldots & \ldots & . .\end{array}$

Lousame.

Malpica de Bengantiños ... ... ..

Mañión.

Corcubióni ...

3.012

7.020

3.612

$\begin{array}{lllll}\text { Santiago.. } & \ldots & \ldots & \ldots & \ldots\end{array}$

4.739

Corcubión $. . . \quad \ldots . . . .$.

6.093

Ordenes.

5.309

Betanzos.

$4.48 \mathrm{I}$

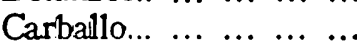

4.192

4.045

Noya.

6.743

Carballo...

7.460

4.433

Mesía.

$\begin{array}{lllll}\text { Ort:guoira } & . . & \ldots & \ldots & \ldots \\ \text { Ordenes... } & \ldots & \ldots & \ldots & \ldots\end{array}$

Miño

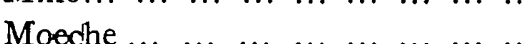

$\begin{array}{lllllllll}\text { Monfero... } & \ldots & \ldots & \ldots & \ldots & \ldots & \ldots & . .\end{array}$

Puentedeume ... $\ldots . .$.

6.409

5.733

E1 Ferrol del Caudillo.

Puentedeume ... $\ldots \ldots$

3,819

7.508

$\begin{array}{lllllllll}\text { Mugía } & \ldots & \ldots & \ldots & \ldots & \ldots & \ldots & \ldots & \ldots\end{array}$

$\begin{array}{lllllllll}\text { Oroso... } & \ldots & \ldots & \ldots & \ldots & \ldots & \ldots & \ldots & . .\end{array}$

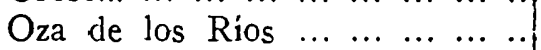

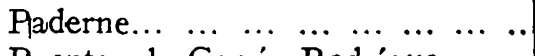

Puentes de Garcia Rodríguez... ..

$\begin{array}{lllllllll}\text { Rois... } & \ldots & \ldots & \ldots & \ldots & \ldots & \ldots & \ldots & . .\end{array}$

San Saturnino...

$\begin{array}{llllllll}\text { Santiso } \ldots & \ldots & \ldots & \ldots & \ldots & \ldots & \ldots & . .\end{array}$

$\begin{array}{lllllllll}\text { Sobrado... } & \ldots & \ldots & \ldots & \ldots & \ldots & \ldots & . .\end{array}$

$\begin{array}{llllllll}\text { Somozas... } & \ldots & \ldots & \ldots & \ldots & \ldots & \ldots & \ldots\end{array}$

$\begin{array}{lllllllll}\text { Toques } & \ldots & \ldots & \ldots & \ldots & \ldots & \ldots & \ldots & \ldots\end{array}$

$\begin{array}{llllllll}\text { Tordoya } . . . & \ldots & \ldots & \ldots & \ldots & \ldots & \ldots & \ldots\end{array}$

Corcubión $\ldots . . . \quad \ldots \quad \ldots$

Ordenes... $\ldots \ldots \ldots \ldots$

$7 \cdot 371$

4.228

Betanzos.

6.316

Betanzos.. ... $\ldots \ldots \ldots$

5.265

5.491

Padrón.

$6.69 \mathrm{r}$

El Ferrol del Caudillo.

Arzúa:

6.676

4.848

Atzúa

El Ferrol del Caudillo.

6.468

Arzúa

$4.54 \mathrm{I}$

3.393

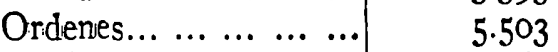

Touro.

Arzúa

7.767

6I.II 5,57

4I.8I 4,53

$69.848,93$

$56.335,93$

$71.000,00$

$75.827,82$

I $3.879,97$

$49.014,09$

65.858 .95

$68.500,81$

81.173,00

$189.699,98$

87.205 .93

$49.802,18$

$75 \cdot 570$, II

$44.751, \infty 0$

59.724 .94

I $38.152,36$

$55.835,07$

$71.999,68$

$71.670,09$

$97 \cdot 337,94$

$95.000,00$

93. 109,00

$59.377,92$

51.536 , IO

51.923 .00

48.793,57

$44.122,92$

$90.956,9$ I 


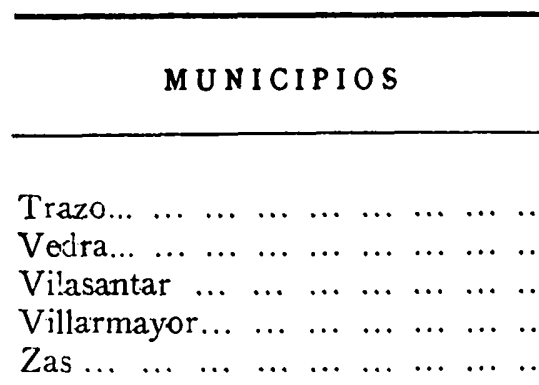

\section{PROVINICIA DE CUENICA}

Aiberca de Záncara (La)

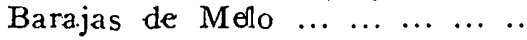

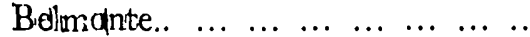

Buenache de Alarcón ... ... .... ...

Camp:ilo de Allobuey.. .........

$\begin{array}{lllllll}\text { Casasimarro.. } & \ldots & \ldots & \ldots & \ldots & \ldots & . .\end{array}$

$\begin{array}{lllllll}\text { Enguídanos... } & \ldots & \ldots & \ldots & \ldots & \ldots & \ldots\end{array}$

Fuente de Pedro Naharro.. ... ..

Hinojosos (Los).

$\begin{array}{llllllll}\text { Honrubia.. } & \ldots & \ldots & \ldots & \ldots & \ldots & \ldots & . .\end{array}$

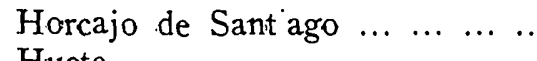

$\begin{array}{llllllllll}\text { Huete.. } & \ldots & \ldots & \ldots & \ldots & \ldots & \ldots & \ldots & . .\end{array}$

$\begin{array}{lllllllll}\text { Iniesta } & \ldots & \ldots & \ldots & \ldots & \ldots & \ldots & \ldots & \ldots\end{array}$

$\begin{array}{lllllllll}\text { Landete } & \ldots & \ldots & \ldots & \ldots & \ldots & \ldots & \ldots & \ldots\end{array}$

$\begin{array}{lllllllll}\text { Ledaña } & \ldots & \ldots & \ldots & \ldots & \ldots & \ldots & \ldots & \ldots\end{array}$

$\begin{array}{llllllll}\text { Mesas }(\operatorname{Las}) . . & \ldots & \ldots & \ldots & \ldots & \ldots & \ldots\end{array}$

$\begin{array}{lllllll}\text { Minglanilla... } & \ldots & \ldots & \ldots & \ldots & \ldots & \ldots\end{array}$

$\begin{array}{lllllllll}\text { Mira... } & \ldots & \ldots & \ldots & \ldots & \ldots & \ldots & \ldots & \ldots\end{array}$

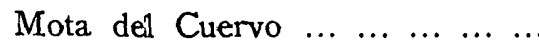

Motilla del Palancar ... $. . . \quad \ldots .$.

Palomares del Campo.. ... ... ..

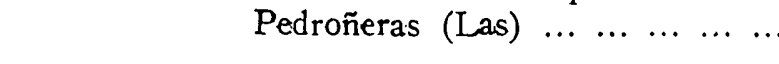

\begin{tabular}{|c|c|c|c|c|}
\hline PARTIDO JUDICIAL & $\begin{array}{c}\text { Población } \\
\text { do } \\
\text { derecho }\end{array}$ & $\begin{array}{l}\text { Sueldo minimo } \\
\text { que le } \\
\text { corresponde }\end{array}$ & Presupuesto on 1943 & OBSERYICIOAES \\
\hline Ordenes... $\ldots \ldots \ldots \ldots$ & 5.317 & 6.000 & $55.667,12$ & \\
\hline $\begin{array}{llllll}\text { Santiago } . . & \ldots & \ldots & \ldots & \ldots\end{array}$ & 6.440 & 7.000 & $73 \cdot 420,43$ & \\
\hline Arzúa $\ldots \begin{array}{lllll} & \ldots & \ldots & \ldots & \ldots\end{array}$ & 4. I95 & 6.000 & 41.994 .75 & \\
\hline Puentedeume $\ldots$ & 3.634 & $5 \cdot 500$ & $50.596,72$ & \\
\hline $\begin{array}{lllll}\text { Corrcubión } & \ldots & \ldots & \ldots & \ldots\end{array}$ & 7.780 & 7.000 & IOI. 648,91 & \\
\hline San Cllemiente... ...... & $2.35^{I}$ & 5.500 & $62.600, \infty$ & \\
\hline 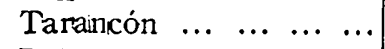 & 2.608 & $5 \cdot 500$ & $79.02 \mathrm{I}, 53$ & \\
\hline Bellmonte $\ldots \begin{array}{lll}\ldots & \ldots & \ldots\end{array}$ & 3.652 & 5.500 & I I I $.495,46$ & \\
\hline Motilla del Pallancar... & 2.263 & $5 \cdot 500$ & $50.903,62$ & \\
\hline Motilla def Palancar... & $3 \cdot 79^{1}$ & $5 \cdot 500$ & $92.502,55$ & \\
\hline Motilla deil Pallancar... & 4.049 & 6.000 & $85.827,37$ & \\
\hline Mortilla del Pallancar... & $2.3^{22}$ & $5 \cdot 500$ & $73.253,26$ & \\
\hline Taralncón $\ldots \ldots c c c$ & 2.662 & 5.500 & $75.458,10$ & \\
\hline Bellmonte $\ldots \begin{array}{llll} & \ldots & \ldots & \ldots\end{array}$ & 2.334 & $5 \cdot 500$ & $72.586,18$ & \\
\hline Saan Cllemente... $\ldots \ldots$ & 2.223 & $5 \cdot 500$ & $55.944,83$ & \\
\hline 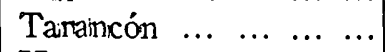 & 4.166 & 6.000 & 122.404 .74 & \\
\hline $\begin{array}{lllllll}\text { Hruete } & \ldots & \ldots & \ldots & \ldots & \ldots\end{array}$ & 3.203 & $5 \cdot 500$ & $I 45.048,22$ & \\
\hline Motilla del Palanoar... & 4.890 & 6.000 & $135: 807,69$ & \\
\hline Cañete... $\quad . . . \quad \ldots \quad \ldots \ldots$ & 2.224 & $5 \cdot 500$ & $64.165,00$ & \\
\hline Motilla del Pallamcar... & 2.842 & $5 \cdot 500$ & $74.251,35$ & \\
\hline Bellmonte $\ldots \begin{array}{lll} & \ldots & \ldots\end{array}$ & 2.992 & $5 \cdot 500$ & $86.555,93$ & \\
\hline Motilla dell Pallancar... & 3.474 & $5 \cdot 500$ & $122.470,90$ & \\
\hline Cañete... $\ldots . \ldots \ldots$ & 2.605 & $5 \cdot 500$ & $89.077,89$ & \\
\hline Biellmonte $\ldots \ldots \ldots$ & 4.470 & 6.000 & $163.826,36$ & \\
\hline Motilla defl Pallancar... & 3.959 & $5 \cdot 500$ & $137.494,00$ & \\
\hline Huete $\ldots \ldots \ldots \ldots$ & 2.020 & $5 \cdot 500$ & $5^{1.095,02}$ & \\
\hline 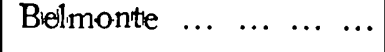 & TA ... $4.95^{\circ}$ & 6.000 & I $37.137,10$ & \\
\hline
\end{tabular}




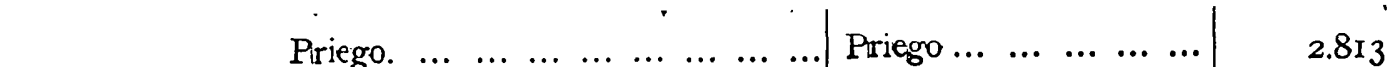
Provencio $(\mathrm{El}) \ldots$ Quintanar del Rey.

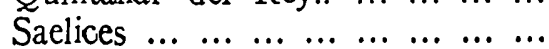

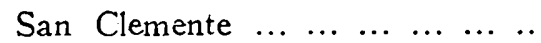
San Lorenzo de la Parrilla ... ...

Santa Cruz de Moya

Santa María dell Campo Rus

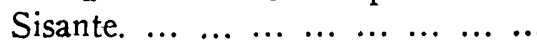

$\begin{array}{llllllll}\text { Tarancón.. } & \ldots & \ldots & \ldots & \ldots & \ldots & \ldots & . .\end{array}$

Torrejoncillo del Rey...

Valverde del Júcar.

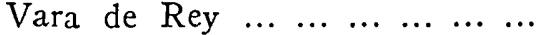

Vllamayor de Santiago ... ... ...

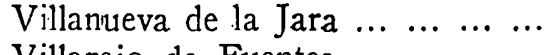

Villarejo de Fuentes ... ... .....

San Clemente... ... ... 4.037

Motilla del Palancar... $\quad 4.810$

Tarancón ...

San Clemente... ......

Cwenca...

Cañete... $\quad \ldots \quad \ldots \quad \ldots \ldots$

San Clemente... ......

San Clemente... ......

Taraincón $\quad \ldots \quad \ldots \quad \ldots .$.

$\begin{array}{llllll}\text { Huete } & \ldots & \ldots & \ldots & \ldots & \ldots\end{array}$

San Clemente... ......

San Clemente... ......

Taraincón ...

Motilla dell Palancar...

Belmontbe ... $\ldots . . . . .$.

\section{PROVINCIA DE GERONA}

Amer.

\begin{tabular}{lllllllll} 
Angl ${ }^{\prime}$ & $\ldots$ & $\ldots$ & $\ldots$ & $\ldots$ & $\ldots$ & $\ldots$ & $\ldots$ & $\ldots$ \\
Angl & $\ldots$ & $\ldots$ & $\ldots$ & $\ldots$ & $\ldots$ & $\ldots$ & $\ldots$ & $\ldots$ \\
\hline
\end{tabular}

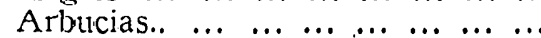

$\begin{array}{lllllllll}\text { Bañolas... } & \ldots & \ldots & \ldots & \ldots & \ldots & \ldots & \ldots & \ldots\end{array}$

$\begin{array}{llllllll}\text { Begudáa... } & \ldots & \ldots & \ldots & \ldots & \ldots & \ldots & \ldots\end{array}$

$\begin{array}{llllllll}\text { Bescanó... } & \ldots & \ldots & \ldots & \ldots & \ldots & \ldots & \ldots\end{array}$

$\begin{array}{llllllll}\text { Bisbal (La) } \ldots & \ldots & \ldots & \ldots & \ldots & \ldots & \ldots\end{array}$

$\begin{array}{lllllllll}\text { Blanes. } & \ldots & \ldots & \ldots & \ldots & \ldots & \ldots & \ldots & \ldots\end{array}$

Caildas de la Malavella ... ... ...

$\begin{array}{llllllll}\text { Calonge... } & \ldots & \ldots & \ldots & \ldots & \ldots & \ldots & \ldots\end{array}$

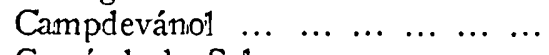

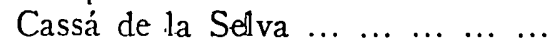

Castelló de Ampurias...

'Celrá.

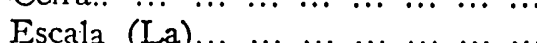

Gerona... ... ........

Santa Coloma Farnés. Santa Coloma Farnés.

Gerona... $\ldots . . . . . . .$.

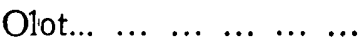

Gdrona... $\ldots \ldots \ldots$

La Bisbal ... $\ldots . . . . .$.

Santa Coloma Farnés..

Santa Coloma Farnés..

La Bisbal ...

Puigcerdá $\ldots \ldots \ldots$

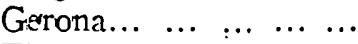

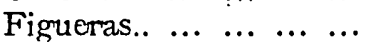

Gerona... $\ldots \ldots \ldots$

$\begin{array}{lllll}\text { Gerona... } & \ldots & \ldots & \ldots & \ldots\end{array}$ 


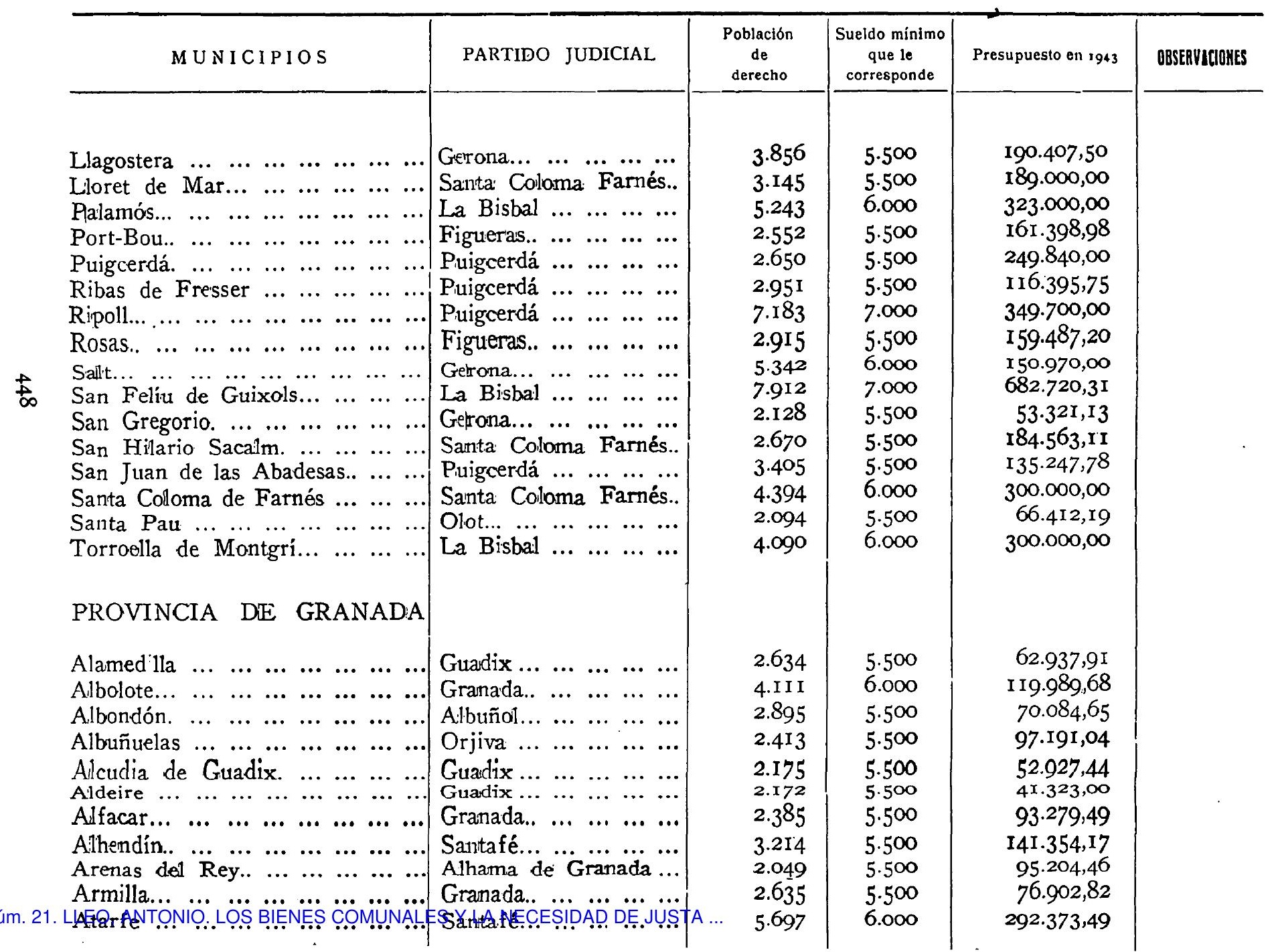




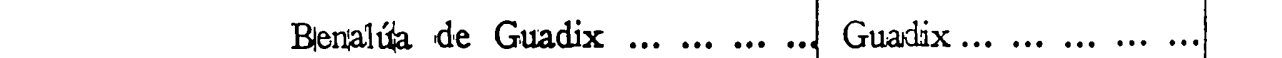

\section{Benamaurel...}

Baza..

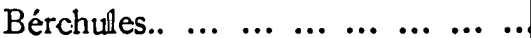

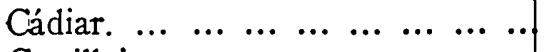

$\begin{array}{llllll}\text { Ujijar } & \ldots & \ldots & \ldots & \ldots & \ldots\end{array}$

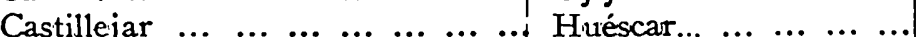

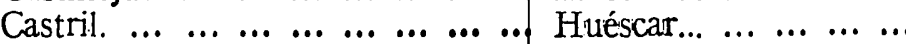

Cogollos de la Vega .............

Gramadia.. ... ... ... ...

$2.17 \mathrm{I}$

\begin{tabular}{llllllll} 
Colomera. & $\ldots$ & $\ldots$ & $\ldots$ & $\ldots$ & $\ldots$ & $\ldots$ &.. \\
\hline
\end{tabular}

Cortes de Baza.

$\begin{array}{lllll}\text { Iznalloz... } & \ldots & \ldots & \ldots & \ldots\end{array}$

4.256

6.000

$98.687,87$

I82.347,27

$44.764,05$

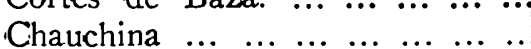

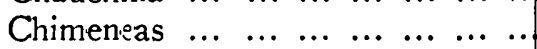

Churriana de Ja Vega... ... ... ...

\begin{tabular}{lllllllll} 
Dúrcal. & $\ldots$ & $\ldots$ & $\ldots$ & $\ldots$ & $\ldots$ & $\ldots$ & $\ldots$ & $\ldots$ \\
Fonelas & $\ldots$ & $\ldots$ & $\ldots$ & $\ldots$ & $\ldots$ & $\ldots$ & $\ldots$ & $\ldots$ \\
\hline
\end{tabular}

4.221

Santafé... ... ... ......

3.712

3.275

Alhama de Granada

5.500

$107.722,55$

II $4.248,70$

II $8.635,23$

$68.617,85$

$72.449,98$

2.779

5.224

2.434

2.892

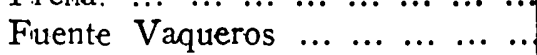

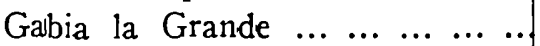

$\begin{array}{lllllllll}\text { Gallera } & \ldots & \ldots & \ldots & \ldots & \ldots & \ldots & \ldots & \ldots \\ \end{array}$

Baza....................

3.227

4.516

Santafé...

4.504

5.902

4.070

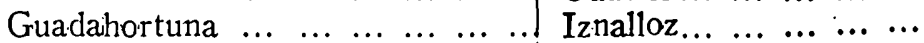

6.000

5.500

$5 \cdot 500$

5.500

6.000

I25.533,49

$76.168,66$

$52.000,00$

5.500

5.500

I $29.500,00$

I $50.097,86$

$211.190,04$

$\mathrm{I} 77.957,69$

I $47.143,37$

$69.196,90$

$\begin{array}{lllll}\text { Motril... } & \ldots & \ldots & \ldots & \ldots\end{array}$

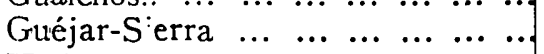

Huéneja..

Granada.. $\quad \ldots \quad \ldots \quad \ldots \quad \ldots$

Guadlix

2.726

4.033

3.466

$\begin{array}{lllllll}\text { Huétor Tájar } & \ldots & \ldots & \ldots & \ldots & \ldots & \ldots\end{array}$

$\begin{array}{lllllllll}\text { Itrabo. } & \ldots & \ldots & \ldots & \ldots & \ldots & \ldots & \ldots & \ldots\end{array}$

$\begin{array}{llllllll}\text { Iznalloz } & \ldots & \ldots & \ldots & \ldots & \ldots & \ldots & \ldots\end{array}$

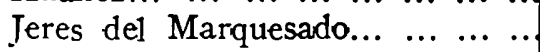

$\begin{array}{lllllll}\text { Lacalahorra... } & \ldots & \ldots & \ldots & \ldots & \ldots & \ldots\end{array}$

$\begin{array}{llllllll}\text { Lanijarón. } & \ldots & \ldots & \ldots & \ldots & \ldots & \ldots & \ldots\end{array}$

$\begin{array}{llllllllll}\text { Lapeza } & \ldots & \ldots & \ldots & \ldots & \ldots & \ldots & \ldots & \ldots\end{array}$

\begin{tabular}{llllllll} 
Maracena. & $\ldots$ & $\ldots$ & $\ldots$ & $\ldots$ & $\ldots$ & $\ldots$ & $\ldots$ \\
\hline
\end{tabular}

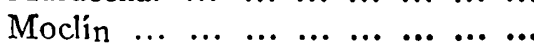

$\begin{array}{llllllll}\text { Molvízar.. } & \ldots & \ldots & \ldots & \ldots & \ldots & \ldots & \ldots\end{array}$

$\begin{array}{llllll}\text { Loja. } & \ldots & \ldots & \ldots & \ldots & \ldots \\ \text { L } & & \end{array}$

$5.02 \mathrm{r}$

2.195

$\begin{array}{lllll}M o t r i l . . . & \ldots & \ldots & \ldots & \ldots\end{array}$

6.634

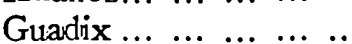

$\begin{array}{lllll}\text { Guadix ... } & \ldots & \ldots & \ldots & \ldots\end{array}$

3.301

2.283

5.273

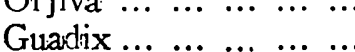

2.036

4. 190

Granada.. ... $\ldots \ldots \ldots$

$\begin{array}{lllll}\text { Motril... } & \ldots & \ldots & \ldots & \ldots\end{array}$

2.260

กั

Monachil..

Gramada.

2.522

6.000

6.000

5.500

6.000

5.500

6.000

$85 \cdot 353,22$

$82.743,61$

I72.401,29

$5.500 \quad 38.251,73$

7.000

$362.603,09$

$5 \cdot 500$

5.500

6.000

$87.846,60$

49.5 II, 97

210.739,72

$83.294,97$

$6.000 \quad 259.074,14$

$6.000 \quad \mathrm{I} 23.555,22$

$5.500 \quad 47.171,65$

5.500

$62.8 \mathrm{I} 6,78$ 


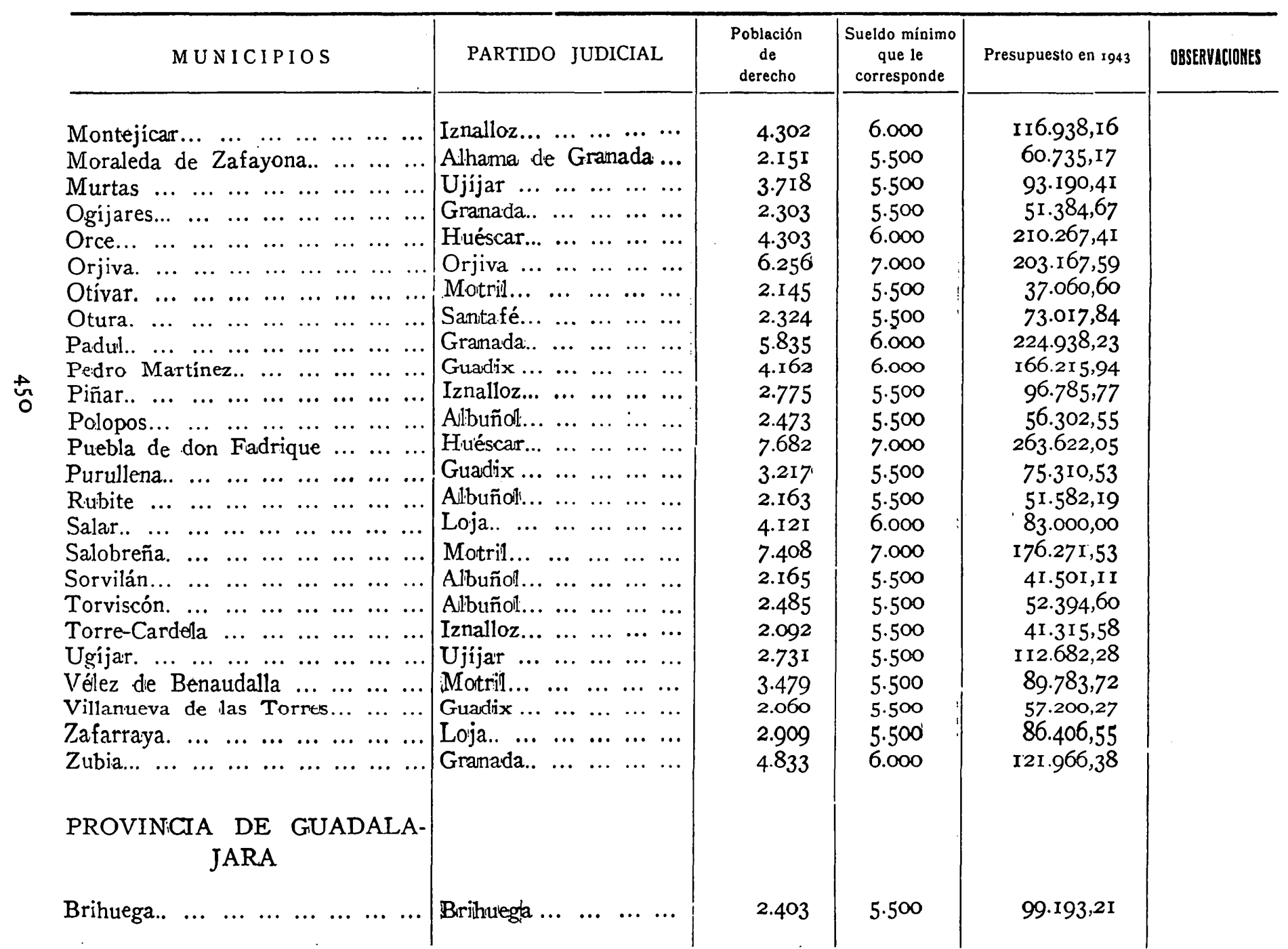




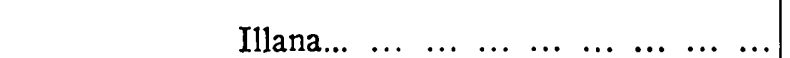

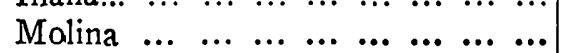
$\begin{array}{llllllll}\text { Mondéjar. } & \ldots & \ldots & \ldots & \ldots & \ldots & \ldots & \ldots\end{array}$

$\begin{array}{lllllllll}\text { Pastrana.. } & \ldots & \ldots & \ldots & \ldots & \ldots & \ldots & \ldots\end{array}$

$\begin{array}{llllllll}\text { Sacedón } . . & \ldots & \ldots & \ldots & \ldots & \ldots & \ldots & \ldots\end{array}$

$\begin{array}{llllllll}\text { Sigüenza.. } & \ldots & \ldots & \ldots & \ldots & \ldots & \ldots & \ldots\end{array}$

\section{PROVINCIA DE GUIPUZCOA}

$\begin{array}{llllllll}\text { Andoain... } & \ldots & \ldots & \ldots & \ldots & \ldots & \ldots & \ldots\end{array}$

$\begin{array}{lllllll}\text { Arechavaleta.. } & \ldots & \ldots & \ldots & \ldots & \ldots & \ldots\end{array}$

$\begin{array}{llllllllll}\text { Ataun } & \ldots & \ldots & \ldots & \ldots & \ldots & \ldots & \ldots & \ldots & \ldots\end{array}$

$\begin{array}{llllllllll}\text { Aya } & \ldots & \ldots & \ldots & \ldots & \ldots & \ldots & \ldots & \ldots & \ldots\end{array}$

$\begin{array}{llllllll}\text { Beasain... } & \ldots & \ldots & \ldots & \ldots & \ldots & \ldots & \ldots\end{array}$

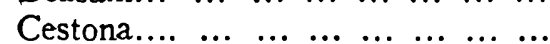

$\begin{array}{llllllll}\text { Deva.. } & \ldots & \ldots & \ldots & \ldots & \ldots & \ldots & \ldots\end{array}$

$\begin{array}{lllllllll} & \text { Elgó bar... } & \ldots & \ldots & \ldots & \ldots & \ldots & \ldots & \ldots\end{array}$

$\begin{array}{llllllll}\text { Escoriaza.. } & \ldots & \ldots & \ldots & \ldots & \ldots & \ldots & \ldots\end{array}$

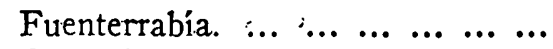

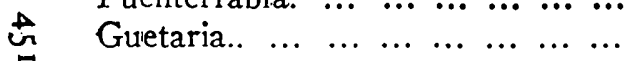

$\begin{array}{lllllllll}\text { Hernani... } & \ldots & \ldots & \ldots & \ldots & \ldots & \ldots & \ldots\end{array}$

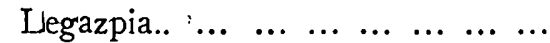

$\begin{array}{llllllllll}\text { Lezo... } & \ldots & \ldots & \ldots & \ldots & \ldots & \ldots & \ldots & \ldots\end{array}$

$\begin{array}{llllllll}\text { Motrico } & . . & \ldots & \ldots & \ldots & \ldots & \ldots & \ldots\end{array}$

\begin{tabular}{lllllllll} 
Oñate.. & $\ldots$ & $\ldots$ & $\ldots$ & $\ldots$ & $\ldots$ & $\ldots$ & $\ldots$ & $\ldots$ \\
\hline
\end{tabular}

$\begin{array}{llllllllll}\text { Orio... } & \ldots & \ldots & \ldots & \ldots & \ldots & \ldots & \ldots & \ldots\end{array}$

$\begin{array}{lllllllll}\text { Oyarzun... } & \ldots & \ldots & \ldots & \ldots & \ldots & \ldots & \ldots & . .\end{array}$

$\begin{array}{llllllll}\text { Placencia... } & \ldots & \ldots & \ldots & \ldots & \ldots & \ldots & \ldots\end{array}$

\begin{tabular}{lllllllll} 
Urnieta &.. & $\ldots$ & $\ldots$ & $\ldots$ & $\ldots$ & $\ldots$ & $\ldots$ & $\ldots$ \\
\hline
\end{tabular}

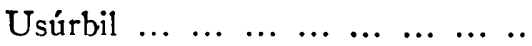

$\begin{array}{llllllll}\text { Villabona.. } & \ldots & \ldots & \ldots & \ldots & \ldots & \ldots & \ldots\end{array}$

Villafranca de Oria.

V'llarreal de Urrechu.

$\begin{array}{ccccc}\text { Tolosa } & . . & \ldots & \ldots & \ldots\end{array}$

$\begin{array}{lllll}\text { Vergara... } & . . & \ldots & \ldots & \ldots\end{array}$

$\begin{array}{llllll}\text { Tolosa } & . . & . . & \ldots & \ldots & \ldots\end{array}$

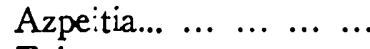

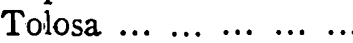

$\begin{array}{lllll}\text { Azpeitia... } & . . & . . & . . & \ldots \\ & \text { Azpein }\end{array}$

$\begin{array}{lllll}\text { Azpe:tia... } & . . & \ldots & \ldots & \ldots\end{array}$

$\begin{array}{llllll}\text { Vergara... } & . & \ldots & \ldots & \ldots & \ldots\end{array}$

$\begin{array}{lllll}\text { Vergara.. } & . . & . . & . . & \ldots\end{array}$

San Sebastián..

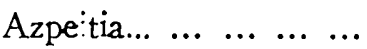

San Sebastián... ... ...

$\begin{array}{lllll}\text { Vergara... } & . . & . . & \ldots & . .\end{array}$

San Sebastián... ... ...

$\begin{array}{lllll}\text { Vergara... } & \ldots & \ldots & \ldots & \ldots\end{array}$

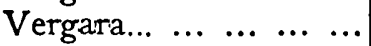

San Sebastián...

San Seljastián...

\begin{tabular}{lllll} 
Vergara... &.. & $\ldots$ & $\ldots$ & $\ldots$ \\
\hline
\end{tabular}

San Sebastián... ... ...

San Sebastián... ... ...

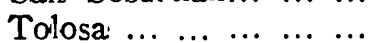

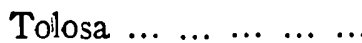

$\begin{array}{lllll}\text { Vergara... } & \ldots & \ldots & \ldots & \ldots\end{array}$ 


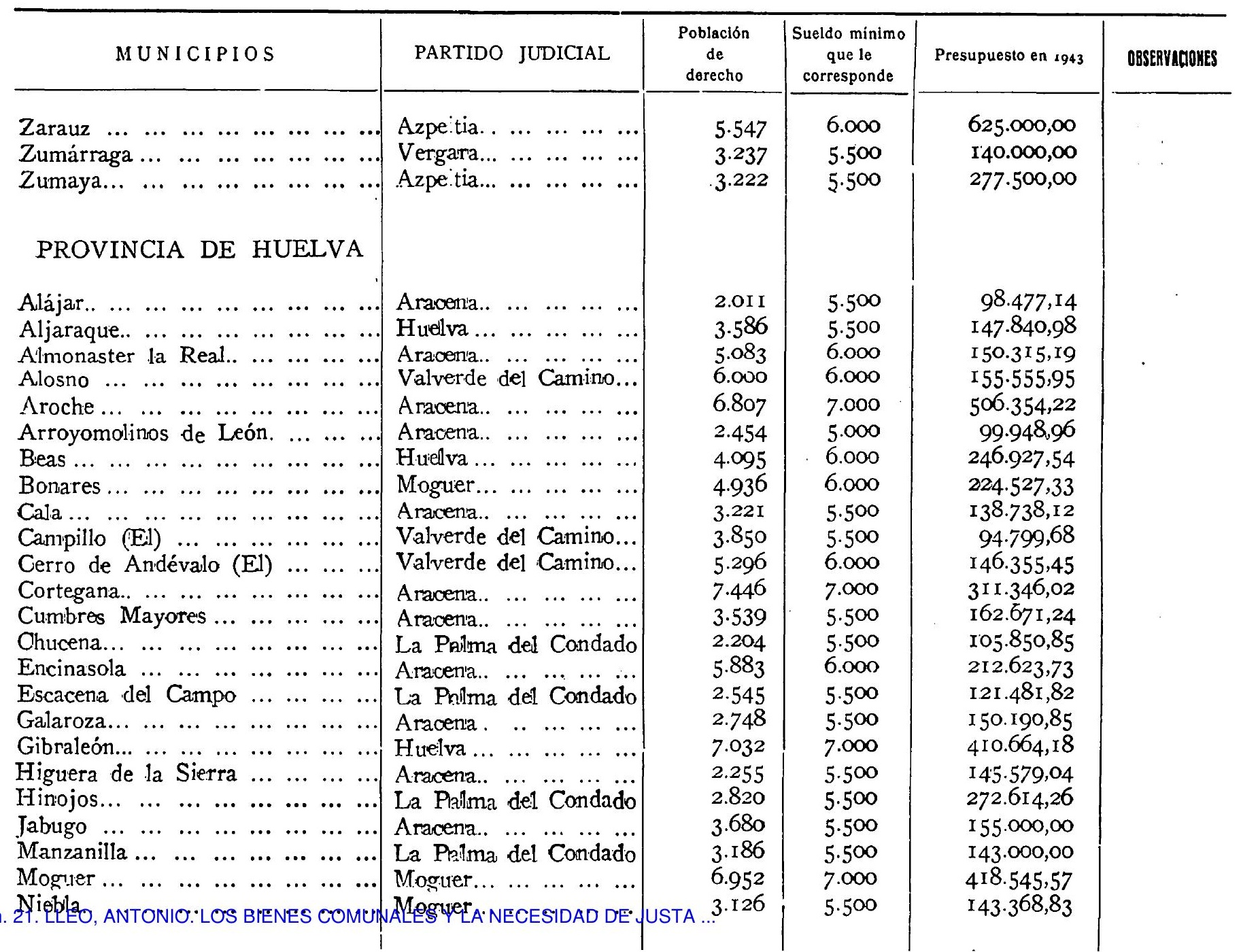


REVL-1945, núm. 2 paldos de ${ }^{A N T O}$ Ta Pontera BIENES COMUNA Paterna del Campo.. ...

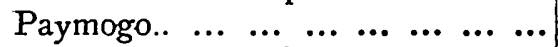

Puebla de Guzmán... ... ... ... ...

$\begin{array}{llllllll}\text { Rociana } . . . & \ldots & \ldots & \ldots & \ldots & \ldots & \ldots & \ldots\end{array}$

Rosal de la Frontera ... ... ... ...

San Bartolomé de la Torre.. ... ...

San Juan del Puerto

Santa Bárbara de Casa.. ... ... ...

Santa Olailla del Cala $\ldots . . . . . . . .$.

Trigueros.

Ff Y.tê .... ...

Valverde del Camino...

Plalma del Condado

.309

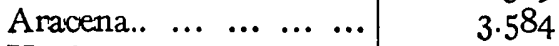

7.000

$\begin{array}{lllll}\text { Huelva } . . . & \ldots & \ldots & \ldots & . .\end{array}$

2.455

$5 \cdot 500$

$5 \cdot 500$

3.976

$5 \cdot 500$

2.5 I 3.500

Aracena.. ... ... ...... 3.832

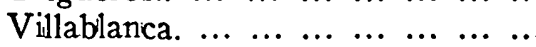

6.403

$5 \cdot 500$

7.000

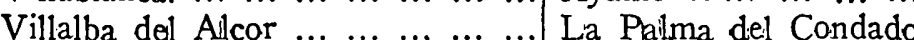

Villanueva de los Castillejos ... ...

$\begin{array}{llllllll}\text { Villarrasa... } & \ldots & \ldots & \ldots & \ldots & \ldots & \ldots & \ldots\end{array}$

Ayamonte ... $\quad . . . \quad \ldots . .$.

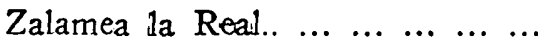

Zufre..

La Pallma del Condado

2.301

4.438

4.063

9.290

$5 \cdot 500$

6.000

6.000

6.342

$5 \cdot 500$

2.422

7.000

Aracena.. ...

\section{PROVINCIA DE HUESCA}

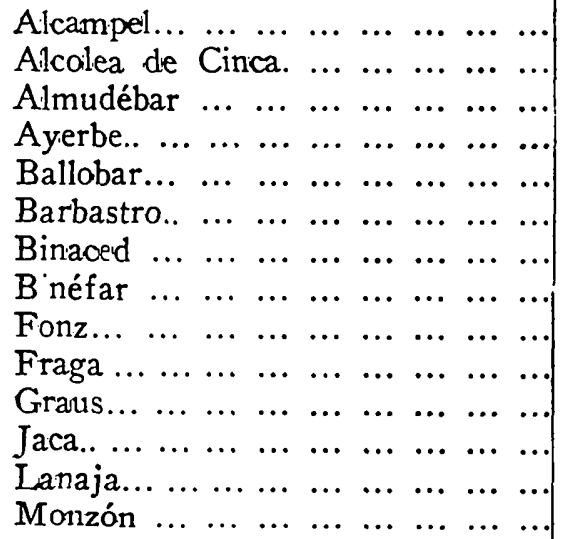

Tamarite die Litrra..

2.166

Fraga $\ldots \ldots \ldots \ldots$

2.016

$5 \cdot 500$

Huesca... $\ldots \begin{array}{llll} & \ldots & \ldots & \ldots\end{array}$

$\begin{array}{lllll}\text { Huesca... } & \ldots & \ldots & \ldots & \ldots\end{array}$

3.205

2.615

$\begin{array}{llllll}\text { Fraga } & \ldots & \ldots & \ldots & \ldots & \ldots\end{array}$

2.I 17

Barbastro ...

6.835

Fraga ... ...

2.338

3.631

Tamarite de Litetra..

Barbastro ...

$\begin{array}{llllll}\text { Fraga } & \ldots & \ldots & \ldots & \ldots & \ldots\end{array}$

7.120

Benabarre... $\ldots . . . .$.

3.474

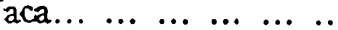

Sariñena.. $\ldots . . . . \quad \ldots . .$.

2.255

Barbastro ...

$60.160,00$ I $72.067,78$

$81.00,00$

2I6.39I, 66

4I $8.941,16$

I 72. I $4 \mathrm{I}, 84$

$67.121,73$

I9I. 466,88

$69.858,20$

I $90.542,01$

$438.670,99$

$62.822,22$

$348.343,49$

$205.035,26$

I $47.770,6 \mathrm{r}$

$203.903,36$

r 99.201 .58

$68.353,40$

$64.88 \mathrm{r}, 22$

I $45 \cdot 332,28$

I $19.628,74$

73.990 .68

$555 \cdot 3$ I 6,5 I

II $2.829,64$

259. 188,00

$63.000,00$

$426.577,95$

I $21.788,70$

$694.821,34$

r07.275, $\mathrm{r} 3$

$260.000,00$ 


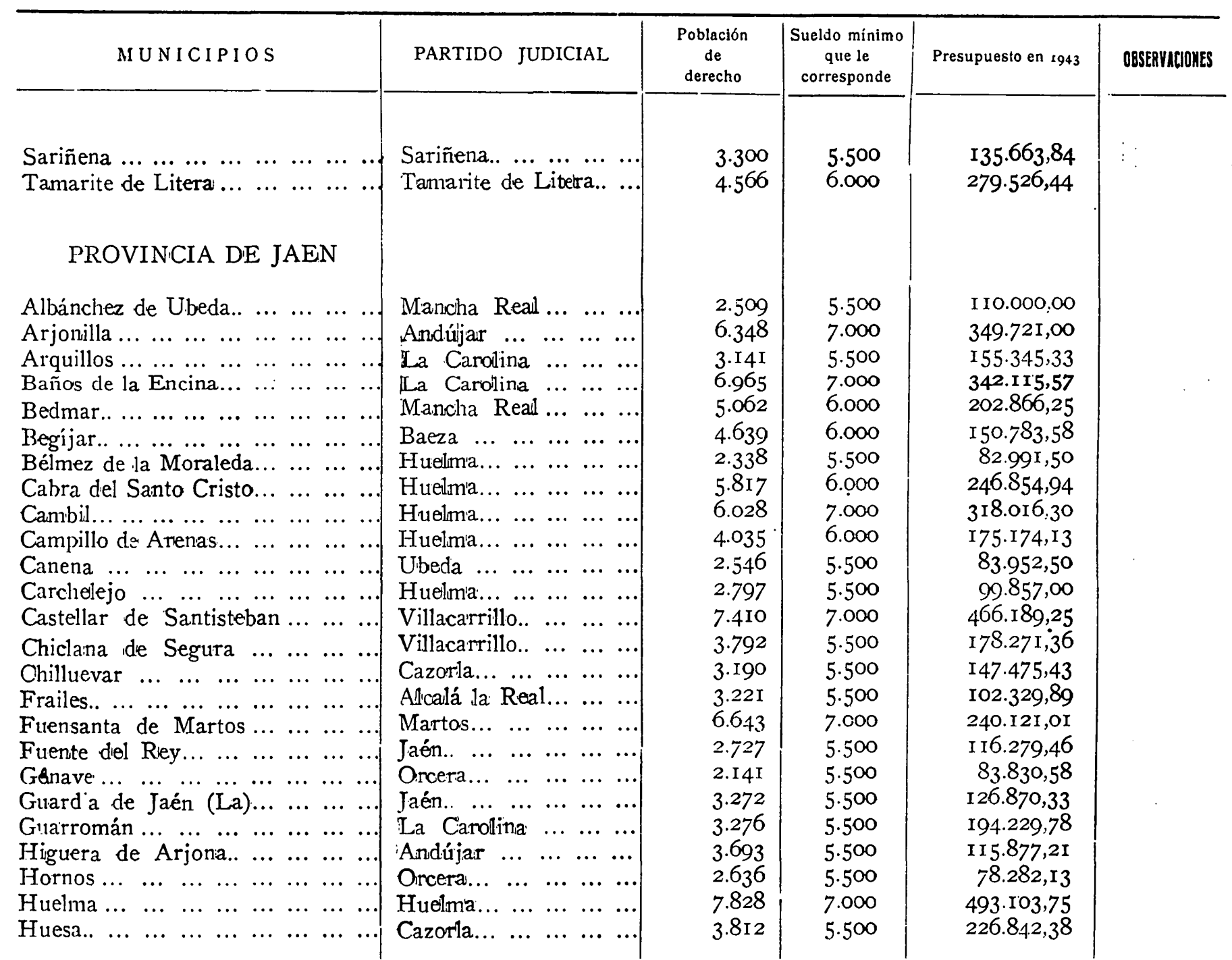




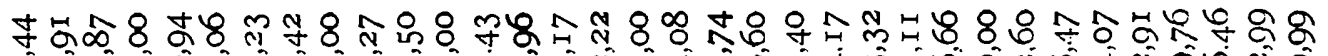

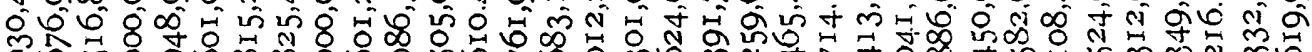
饭

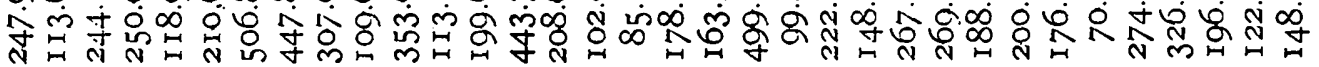

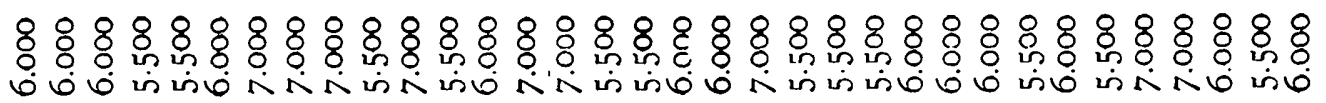

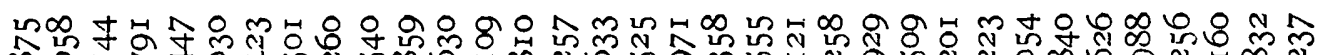
की

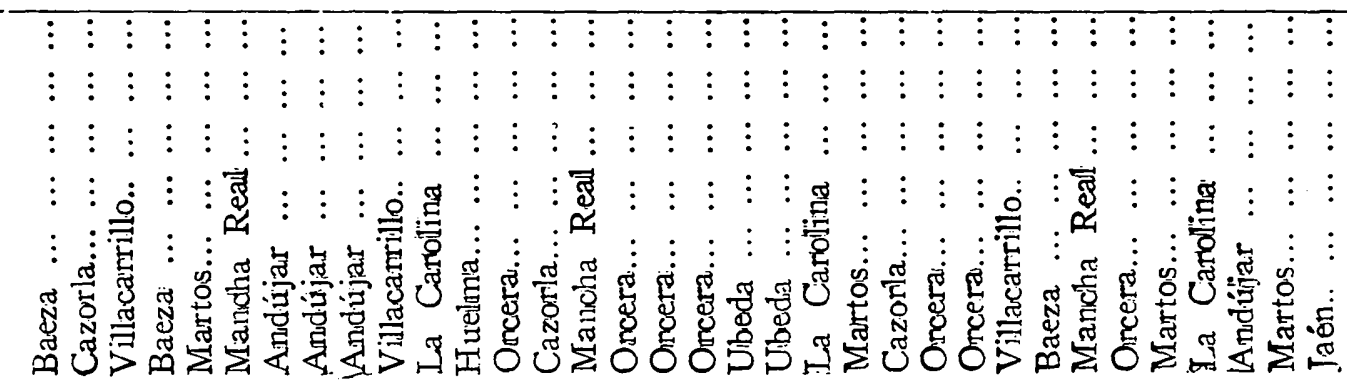

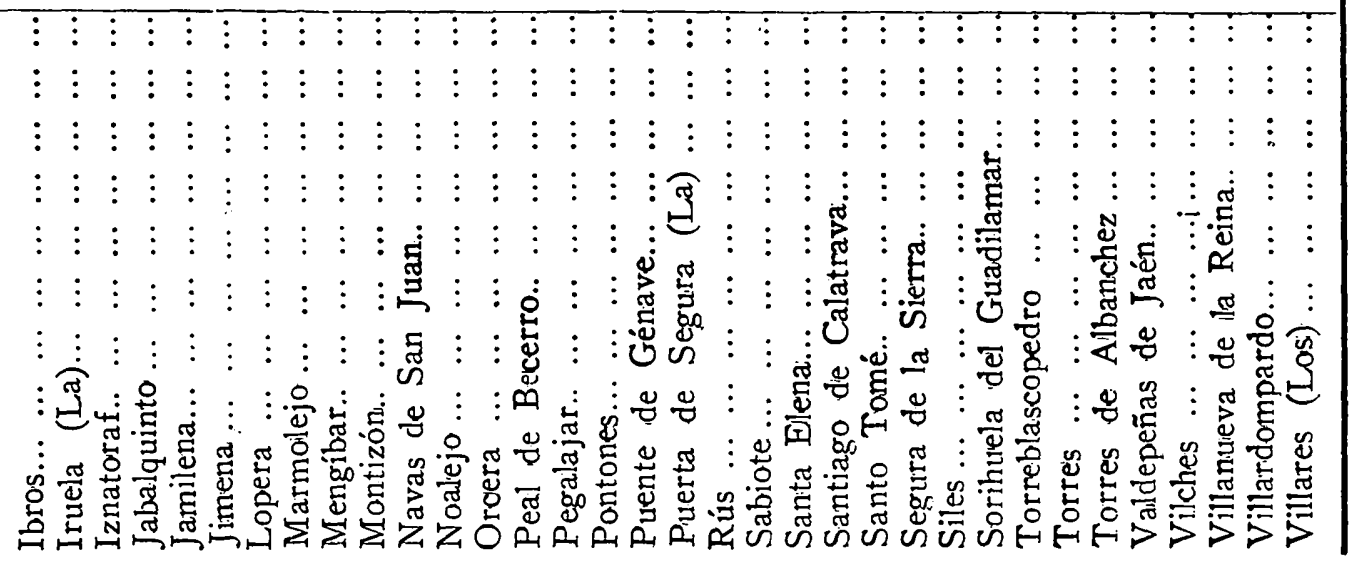




\begin{tabular}{|c|c|c|c|c|c|}
\hline MU N I C I PIOS & PARTIDO JUDICIAL & $\begin{array}{c}\text { Población } \\
\text { de } \\
\text { derecho }\end{array}$ & $\begin{array}{c}\text { Sueldo mínimo } \\
\text { que le } \\
\text { corresponde }\end{array}$ & Presupuesto en 1943 & OBSERYICIONES \\
\hline $\begin{array}{lllllll}\text { Villargordo } & \ldots & \ldots & \ldots & \ldots & \ldots & \ldots\end{array}$ & $\begin{array}{cccccc}\text { Baeza } & \ldots & \ldots & \ldots & \ldots & \ldots\end{array}$ & 4.565 & 6.000 & I $79.503,2 \mathrm{I}$ & \\
\hline $\begin{array}{llllllll}\text { Villarrodrigo.. } & \ldots & \ldots & \ldots & \ldots & \ldots & \ldots\end{array}$ & Orcera... & 2.I IO & $5 \cdot 500$ & 74.863 .74 & \\
\hline \multicolumn{6}{|l|}{ PROVINCIA DE LEON } \\
\hline Abares de la Ribera.. $\ldots \ldots \ldots \ldots$ & Yonterrada... ... ... ... & 3.474 & $5 \cdot 500$ & Faltan datos. & \\
\hline Alija de los Melones ... ... ... ... & La Bañeza... $\ldots . . . .$. & 2.340 & $5 \cdot 500$ & $66.628,75$ & \\
\hline $\begin{array}{llllllll}\text { Arganza... } & \ldots & \ldots & \ldots & \ldots & \ldots & \ldots & \ldots\end{array}$ & Villafranca Bierzo.. ... & 2.487 & $5 \cdot 500$ & $43.059,00$ & \\
\hline $\begin{array}{llllllllll}\operatorname{Armunia} \ldots & \ldots & \ldots & \ldots & \ldots & \ldots & \ldots & \cdots\end{array}$ & $\begin{array}{llllll}\text { León.. } & \ldots & \ldots & \ldots & \ldots & \ldots\end{array}$ & $3 \cdot 3^{12}$ & $5 \cdot 500$ & $46.752,70$ & \\
\hline Bañeza (La)... & La Bañeza... ... ... ... & 6.362 & 7.000 & $460.056,29$ & \\
\hline $\begin{array}{llllllllll}\text { Barjas } & \ldots & \ldots & \ldots & \ldots & \ldots & \ldots & \ldots & \ldots\end{array}$ & Villafranca Bierzo.. ... & 2.379 & $5 \cdot 500$ & $40.081,80$ & \\
\hline Barros de Salas (Los).. ... ... ... & Ponferrada... ... ... ... & 2.076 & $5 \cdot 500$ & $48.081,41$ & \\
\hline 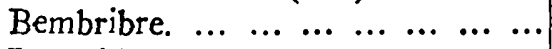 & Ponferrada... ... ... ... & 4.193 & 6.000 & I $37 \cdot 328$, I I & \\
\hline $\begin{array}{lllllllll}\text { Benavides.. } & \ldots & \ldots & \ldots & \ldots & \ldots & \ldots & \ldots\end{array}$ & Astonga... $\ldots \ldots \ldots$ & 4.042 & 6.000 & I I 5.635, I 3 & \\
\hline $\begin{array}{cccccccc}\text { Benuza } \ldots & \ldots & \ldots & \ldots & \ldots & \ldots & \ldots & \ldots\end{array}$ & Ponferrada... $\ldots \ldots \ldots$ & 2.648 & $5 \cdot 500$ & $33.672,48$ & \\
\hline Boca de Huérgano... ......... & Riaño $\ldots \ldots \ldots c c c$ & 2.602 & $5 \cdot 500$ & $30.848,93$ & \\
\hline $\begin{array}{lllllllll}\text { Boñar.. } & \ldots & \ldots & \ldots & \ldots & \ldots & \ldots & \ldots & \ldots\end{array}$ & La Vecilla... $\ldots \ldots \ldots$ & 3.744 & $5 \cdot 500$ & I I I.I 96,6 I & \\
\hline Burgo Ranero (El)... $\ldots \ldots \ldots \ldots$ & 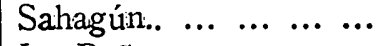 & 2.124 & $5 \cdot 500$ & $50.000,00$ & \\
\hline Bustillo del Páramo $\ldots . . . . . . .$. & La Bañeza... ... ... ... & 2.629 & $5 \cdot 500$ & $3 \mathrm{I} .292,2 \mathrm{I}$ & \\
\hline $\begin{array}{lllllllll}\text { Cacabelos.. } & \ldots & \ldots & \ldots & \ldots & \ldots & \ldots & \ldots\end{array}$ & Villafranca Bierzo.. ... & 3.724 & $5 \cdot 500$ & I70.179,19 & \\
\hline 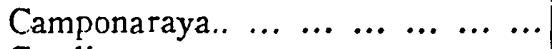 & Villafranca Bierzo.. ... & $2.20 \mathrm{I}$ & $5 \cdot 500$ & $36.988,00$ & \\
\hline $\begin{array}{lllllllll}\text { Candín } & \ldots & \ldots & \ldots & \ldots & \ldots & \ldots & \ldots & \ldots\end{array}$ & Villafranca Bierzo.. ... & $2.09 \mathrm{I}$ & $5 \cdot 500$ & $40.286,00$ & \\
\hline Carraceledo... ... & Villafranca Bierzo.. ... & 3.877 & $5 \cdot 500$ & $38.657,36$ & \\
\hline $\begin{array}{cccccccc}\text { Carrizo } & \ldots & \ldots & \ldots & \ldots & \ldots & \ldots & \ldots\end{array}$ & Astonga... $\ldots \ldots \ldots \ldots$ & 2.497 & $5 \cdot 500$ & $36.976,55$ & \\
\hline $\begin{array}{ccccccc}\text { Castrocalbón.. } & \ldots & \ldots & \ldots & \ldots & \ldots & \ldots\end{array}$ & La Bañeza... ... ... ... & 2.327 & $5 \cdot 500$ & $41.942,95$ & \\
\hline $\begin{array}{llllllll}\text { Castrocontrigo } & \ldots & \ldots & \ldots & \ldots & \ldots & \ldots\end{array}$ & La Bañeza... ... ... ... & 3.229 & $5 \cdot 500$ & $63.43 \mathrm{r}, 87$ & \\
\hline Castropodame $\ldots \begin{array}{llllllll} & \ldots & \ldots & \ldots & \ldots & \ldots\end{array}$ & Ponferrada... $\ldots \ldots \ldots$ & 2.739 & $5 \cdot 500$ & $35.123,25$ & \\
\hline Cimanes del Tejar... $\ldots \ldots \ldots \ldots$ & León.. $\ldots \ldots \ldots c c c c$ & 2.105 & $5 \cdot 500$ & $3 \mathrm{I} \cdot 590,78$ & \\
\hline 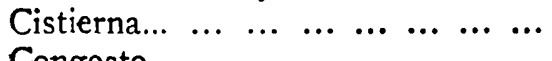 & 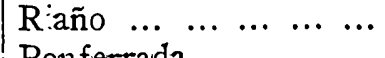 & 4.792 & 6.000 & I $26.496,70$ & \\
\hline$\ldots \ldots \ldots \ldots$ & & $\cdot 2.062$ & $5 \cdot 500$ & $30.508,75$ & \\
\hline
\end{tabular}




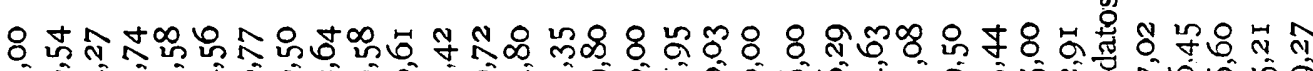

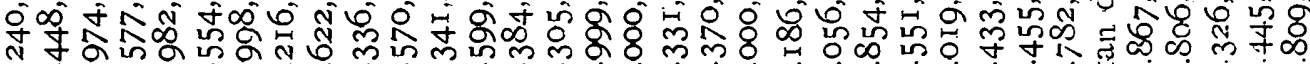

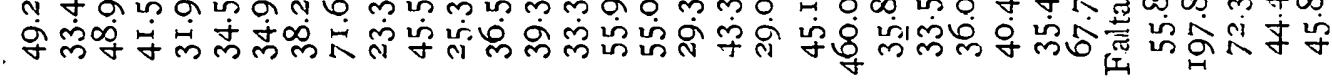

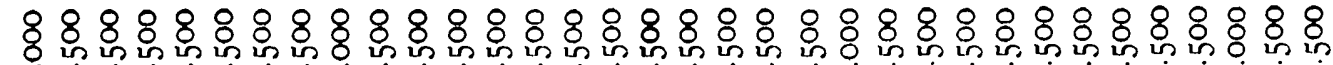
ف ف

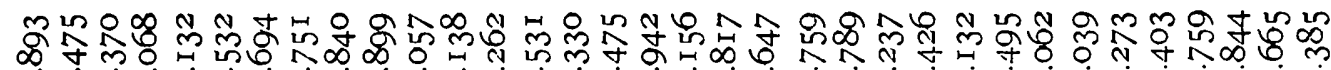

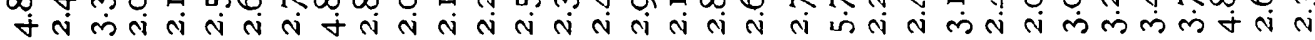

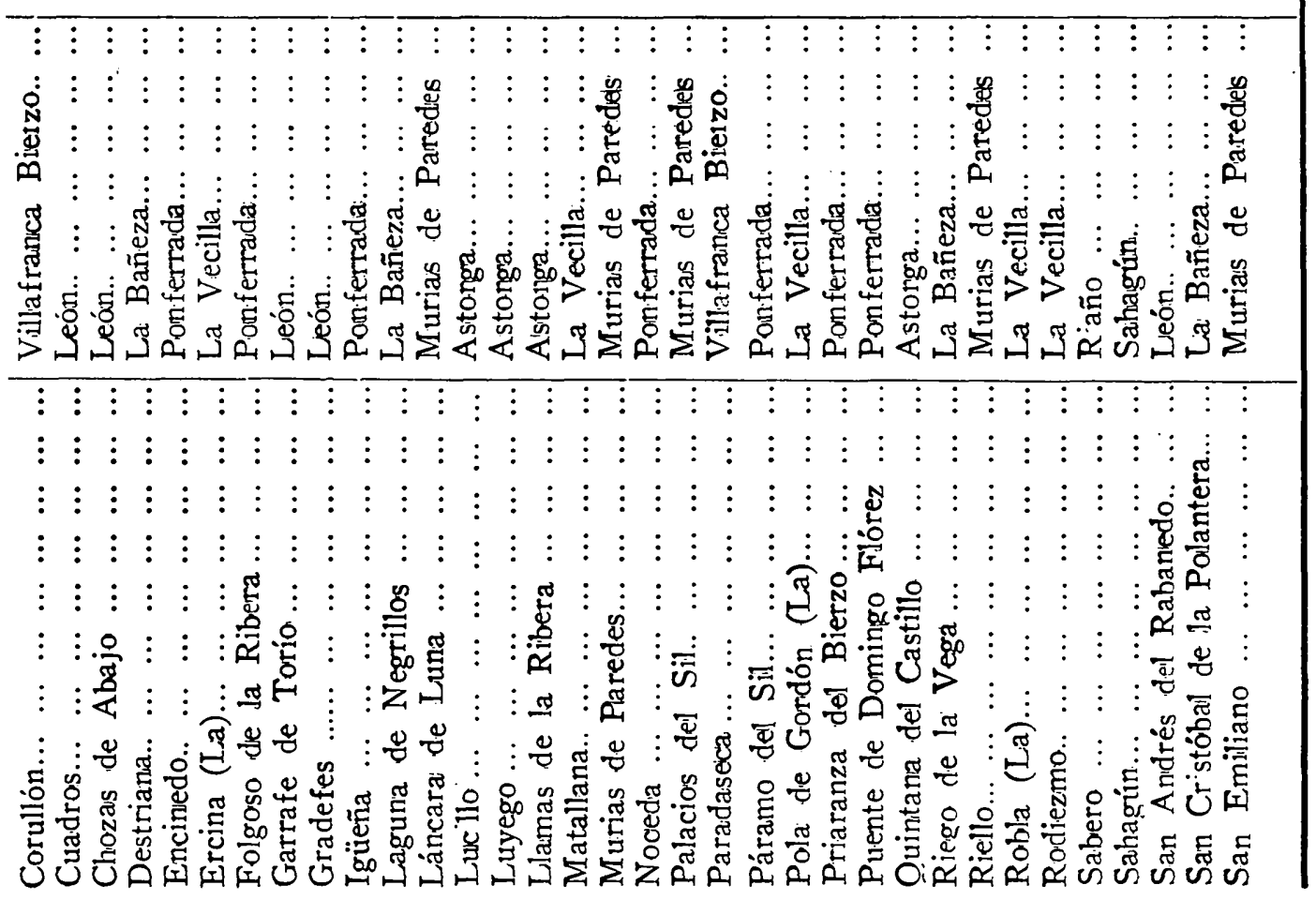




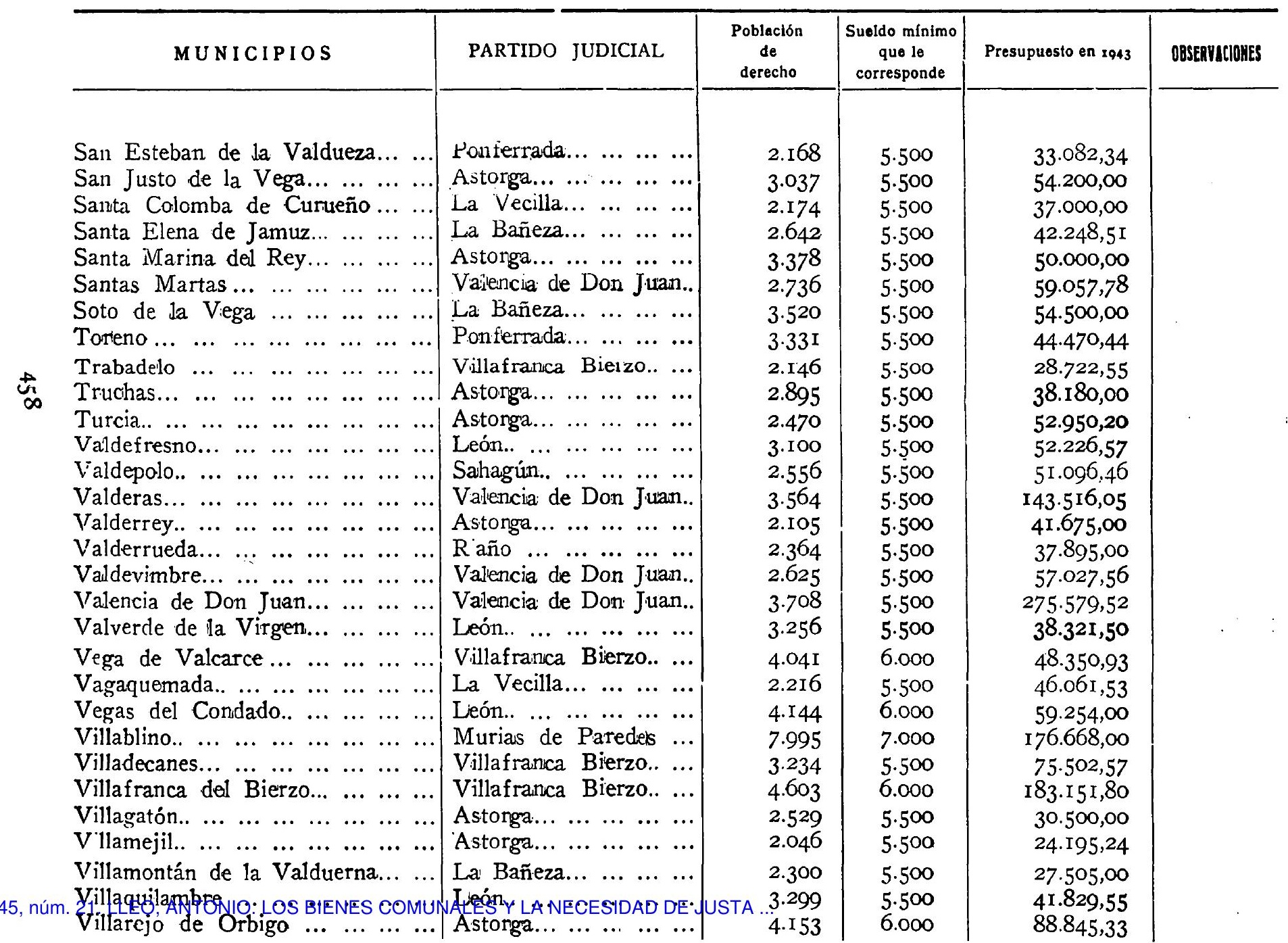


Villares de Orbigo.

. $v$ frasâbariego ... B...

Villaturiel

Astonga.

2.075

$5 \cdot 500$

$34.207,04$

Villazanzo de Valderaduey $\ldots . .$.

$\begin{array}{llllll}\text { León. } & \cdots & \cdots & \ldots & \ldots & \ldots \\ \text { Le } & \ldots & \ldots & \ldots & \ldots\end{array}$

2.414

2.769

2.197

\section{PROVINCIA DE LERIDA}

Agramunt.

Sahagún..

$\ldots \ldots$

$\begin{array}{llllllll}\text { Alcarraz... } & \ldots & \ldots & \ldots & \ldots & \ldots & \ldots & \ldots\end{array}$

$\begin{array}{lllllllll}\text { Alguaire... } & \ldots & \ldots & \ldots & \ldots & \ldots & \ldots & \ldots\end{array}$

$\begin{array}{llllllll}\text { Almacellas } & \ldots & \ldots & \ldots & \ldots & \ldots & \ldots & \ldots\end{array}$

$\begin{array}{lllllllll}\text { Almenar... } & \ldots & \ldots & \ldots & \ldots & \ldots & \ldots & \ldots\end{array}$

$\begin{array}{llllllll}\text { Anglesolla.: } & \ldots & \ldots & \ldots & \ldots & \ldots & \ldots & \ldots\end{array}$

$\begin{array}{llllllllll}\text { Arbeca } & \ldots & \ldots & \ldots & \ldots & \ldots & \ldots & \ldots & \ldots\end{array}$

Artesa de Segre.. ... ... ... ... ...

$\begin{array}{llllllllll}\text { Aytona } & . . & \ldots & \ldots & \ldots & \ldots & \ldots & \ldots & \ldots\end{array}$

$\begin{array}{llllllll}\text { Balaguer... } & \ldots & \ldots & \ldots & \ldots & \ldots & \ldots & \ldots\end{array}$

$\begin{array}{lllllllll}\text { Bellpu:g... } & \ldots & \ldots & \ldots & \ldots & \ldots & \ldots & \ldots\end{array}$

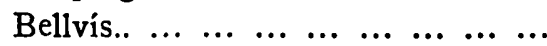

$\leftrightarrow$ Borjas Blancas... $\ldots . . . . . . . . .$.

$\begin{array}{llllllll}\text { Cervera... } & \ldots & \ldots & \ldots & \ldots & \ldots & \ldots & \ldots\end{array}$

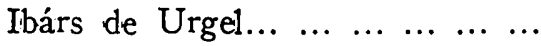

$\begin{array}{lllllllll}\text { Juneda } & \ldots & \ldots & \ldots & \ldots & \ldots & \ldots & \ldots & \ldots\end{array}$

$\begin{array}{lllllllll}\text { Liñola.. } & \ldots & \ldots & \ldots & \ldots & \ldots & \ldots & \ldots & \ldots\end{array}$

$\begin{array}{llllllllll}\text { Mayáls } & . & \ldots & \ldots & \ldots & \ldots & \ldots & \ldots & \ldots & \ldots\end{array}$

$\begin{array}{lllllllll}\text { Mollerusa.. } & \ldots & \ldots & \ldots & \ldots & \ldots & \ldots & \ldots\end{array}$

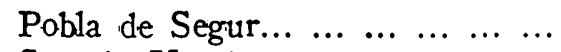

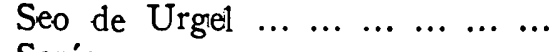

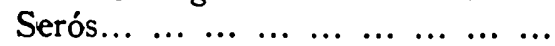

$\begin{array}{lllllllll}\text { Sollsona } & . . & \ldots & \ldots & \ldots & \ldots & \ldots & \ldots & \ldots\end{array}$

$\begin{array}{llllllll}\text { Tárrega... } & \ldots & \ldots & \ldots & \ldots & \ldots & \ldots & \ldots\end{array}$

$\begin{array}{lllllllll}\text { Torregrosa } & \ldots & \ldots & \ldots & \ldots & \ldots & \ldots & \ldots\end{array}$

$\begin{array}{lllllllll}\text { Tremp } & \ldots & \ldots & \ldots & \ldots & \ldots & \ldots & \ldots & \ldots\end{array}$

Balaguer.. ... $\ldots \ldots \ldots$

$\begin{array}{llllll}\text { Lérida } \ldots & \ldots & \ldots & \ldots & \ldots\end{array}$

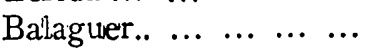

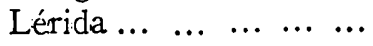

Balaguer.. ... ... ... ...

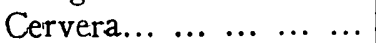

Borjas Blancas..

Bailaguer.

Lérida ... ... ...

Ballaguer.. ...

Cervera... $\ldots . . . . . . .$.

Bailaguer.. ... ... ... ...

Borjas Blancas.. ... ...

Cervera... ... $\ldots . . . .$.

Bailaguer.. ... $\ldots \ldots \ldots$

Borjas Blancas.. ... ...

Ballaguer.. ... ... ... ...

$\begin{array}{llllll}\text { Lérida } \ldots & \ldots & \ldots & \ldots & \ldots\end{array}$

Léridia ...

Tremp ...

Seo de Urgell... ... ...

$\begin{array}{lllll}\text { Léridia ... } & \ldots & \ldots & \ldots & \ldots\end{array}$

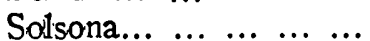

Cervera... ... ... $\ldots . .$.

Borjas Blancas.

Tremp

2.605

3.309

2.618

3.326

2.995

2.039

3.197

2.750

2.329

6.280

3.I 3 I

2.864

4.457

4.878

2.034

$3 \cdot 344$

2.084

2.087

3.387

2.049

3.820

2.654

3.239

$6.2 \mathrm{I} 5$

2.463

$3.55^{8}$

I 48.488, 50 $52.984,5 \mathrm{I}$ I 20.558 .78 I68.8I 5,72

I $20.000,00$

I08.759, 13

I $53.798,79$

97.559 .32

I 34.5 II, 82

$387.250,00$

I64.389, I I

$72.560,14$ $272.937,73$ 4I $4.892,01$ $75.047,38$ $167 \cdot 325,45$ $123.665,93$ I $20.270,00$ 216.301,07 I 99.6 I 9.85 $245.000,00$ I51.660,80 $197.693,80$ $485.6 \mathrm{r} 4,25$ $104 \cdot 370,40$ 2I $2.243,2 \mathrm{I}$ 


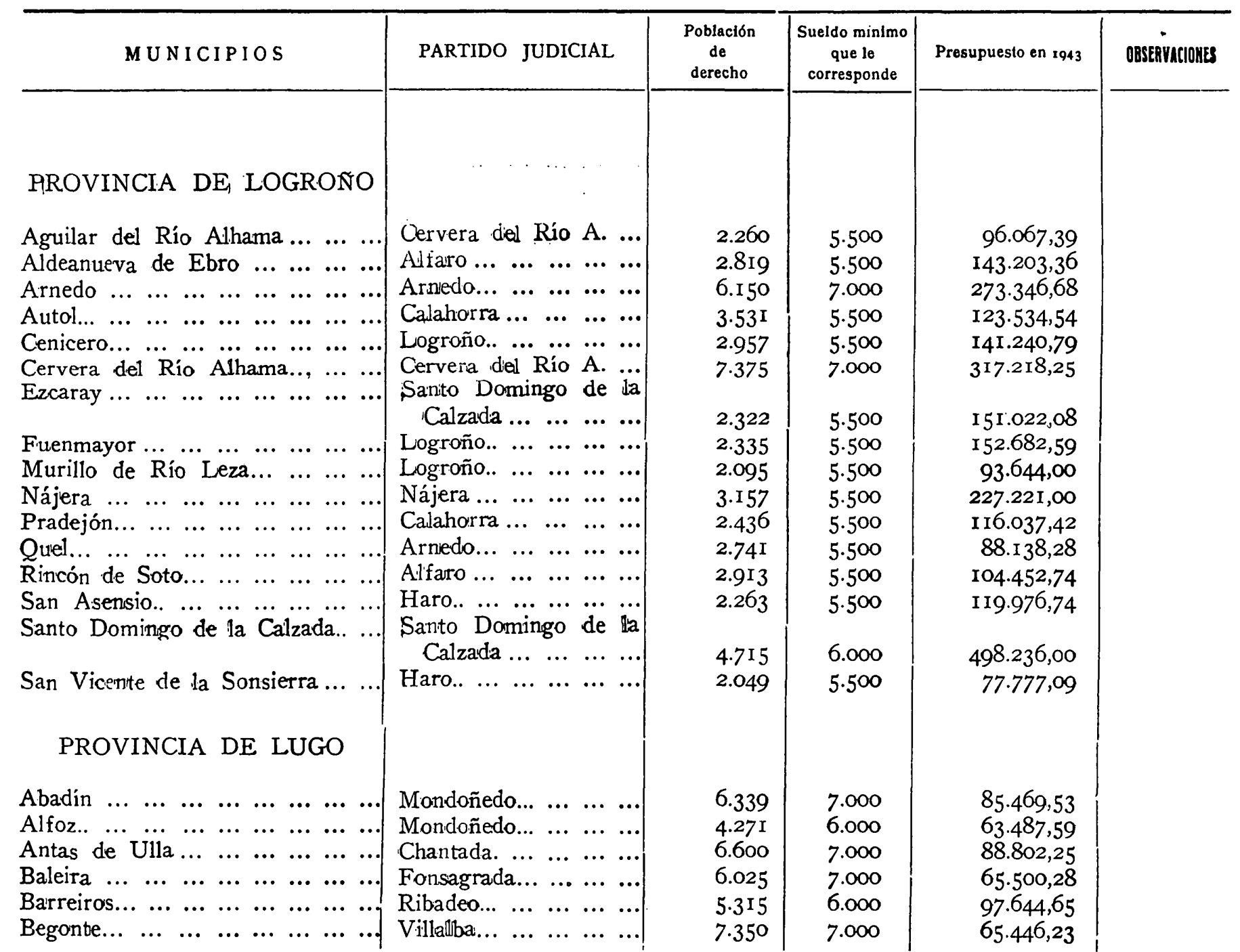




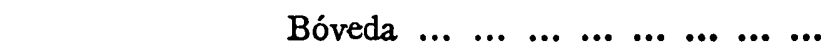
$\begin{array}{lllllllll}\text { Caurel.. } & . . & . . & . . & . . & . . & . . & . . & . .\end{array}$

Cervantes.. ... ... $\ldots . . . . . . . . . .$.

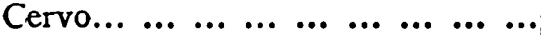

Cospeito... $\ldots . . . . . . . . . . . . . . .$.

Germade... ...

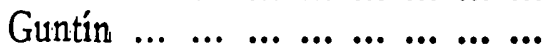

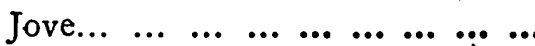

Láncara... ... ...

Lorenzana ...

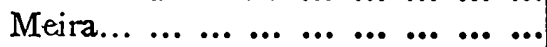

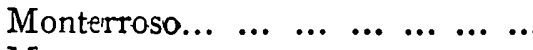

Muras.. ...

Navia de Suarna ... ... ... ... ...

Negueria de Muñiz.. ... ... ... ..

Nogales (Los) ... ... ... ... ... ..

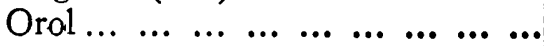

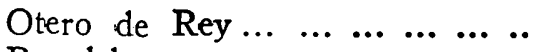

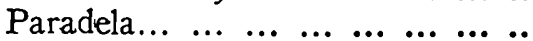

$\begin{array}{llllllll}\text { Páramo } \ldots & \ldots & \ldots & \ldots & \ldots & \ldots & \ldots & \ldots\end{array}$

$\begin{array}{llllllll}\text { Piedrafita.. } & \ldots & \ldots & \ldots & \ldots & \ldots & \ldots & \ldots\end{array}$

\begin{tabular}{llllllllll}
$\mathrm{Pol}$ & $\ldots$ & $\ldots$ & $\ldots$ & $\ldots$ & $\ldots$ & $\ldots$ & $\ldots$ & $\ldots$ & $\ldots$ \\
\hline
\end{tabular}

Puebla del Brollón...

Puertomarín...

Ribas del Sil..

Ribera de Piquin

Ríobarba...

$\begin{array}{llllllll}\text { Riotorto... } & \ldots & \ldots & \ldots & \ldots & \ldots & \ldots & \ldots\end{array}$

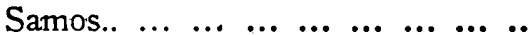

$\begin{array}{lllllllll}\text { Trabada } . . & \ldots & \ldots & \ldots & \ldots & \ldots & \ldots & . .\end{array}$

$\begin{array}{lllllllll}\text { Triacastella } & \ldots & \ldots & \ldots & \ldots & \ldots & \ldots & \ldots\end{array}$

Valle de Oro $\ldots . . . . . . . . . . .$.

$\begin{array}{llllllll}\text { Villameá... } & \ldots & \ldots & \ldots & \ldots & \ldots & \ldots & \ldots\end{array}$

Villaodrid..

draf DitteE aleADentriosus

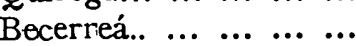

$\begin{array}{lllll}\text { Vivero... } & \ldots & \ldots & \ldots & \ldots\end{array}$

$7.24 \mathrm{I}$

7.989

Villalba...

$5 \cdot 386$

6.000

Lugo... ...........

7.558

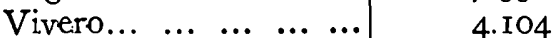

Sarria. ...

Mondoñiedo... .........

7.418
4.605

Fonsagrada... .........

4.605
2.212

Chantada. ...

$\begin{array}{lllll}\text { Vivero... } & \ldots & \ldots & \ldots & \ldots\end{array}$

7.393

3.628

Fonsagrada...

Fonsagrada... ........

7.762

2.105

Bscerreá... ... ... ... ... 5.049

\begin{tabular}{lllll|l} 
Vivero... & $\ldots$ & $\ldots$ & $\ldots$ & $\ldots$ & $\ldots$
\end{tabular}

$\begin{array}{llllll}\text { Lugo. } & . . & \ldots & \ldots & \ldots & \ldots\end{array}$

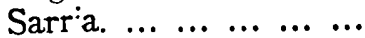

6.295

6.020

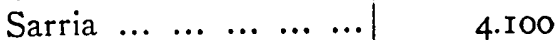

7.000

$80.000,00$

$75 \cdot 538,87$

6.000

$99.912,99$

$52.904,55$

$74.030,00$

6.000

$46.991,28$

7.000

(6). $4.79,03$

78.063 .58

5.500

$47.028,59$

7.000

$78.680,97$

5.500

7.000

$48.24 \mathrm{I}, 65$

$84.000,00$

5.500

32.101,97

$63.490,14$

$87.597,81$

6 I.60r,87

7.000

56.739, I 5

4.632

Becerreá... $\ldots \ldots \ldots \ldots$

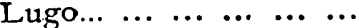

5.203

7.000

$39.070,47$

Quiroga... '..........

7.600

$60.775,80$

6.000

56.17 I, 84

Chantada. ... $\ldots . . . . .$.

$4.4 \mathrm{I} 3$

$92.456,15$

$44.809,78$

Quiroga... ... $\ldots . . . . .$.

Fonsagrada... ... ... ...

4.142

2.240

$\begin{array}{lllll}\text { Vivero... } & \ldots & \ldots & \ldots & \ldots\end{array}$

5.222

Mondoñedo... ... ... ...

4. I93

Sarria. ...

Ribadieo... ... $\ldots \ldots \ldots$

7.999

3.415

Beberreá... ... ... ... ...

Mondioñedo.

3.127

4.606

7.000

6.000

55.760 .47

$29.982,02$

5.500

$63.218,59$

$88.064,86$

6.600

$65.500,00$

$74.347,92$

5.500

$49 \cdot 454,48$

Riliadieo.

$5 \cdot 500$

$78.201,90$

2.365

$50.837,57$

Ribadeo... ... ... ... ...

$4 \cdot 328$

5.500

$90.737,58$ 


\begin{tabular}{|c|c|c|c|c|c|}
\hline MUNICIPIOS & PARTIDO JUDICIAL & $\begin{array}{c}\text { Población } \\
\text { de } \\
\text { derecho }\end{array}$ & $\mid \begin{array}{c}\text { Sueldo minimo } \\
\text { que le } \\
\text { corresponde }\end{array}$ & Presupuesto en $\times 943$ & OBSERYICIOHES \\
\hline PROVINCIA DE MADRID & & & & & \\
\hline $\begin{array}{lllllllll}\text { Arganda } . . . & \ldots & \ldots & \ldots & \ldots & \ldots & \ldots & \ldots\end{array}$ & Chinchón.. $\ldots . . . .6 . .$. & $5 \cdot 4 \mathrm{II}$ & 6.000 & $335 \cdot 782,89$ & \\
\hline Barajas de Madrid... ... ... ... ... & Alcalá de Henares.. ... & 2.274 & $5 \cdot 500$ & $126.004,03$ & \\
\hline Cadalso de los Vidrios... ... ... ... & San. Martín de la V. ... & 2.356 & $5 \cdot 500$ & $128.926,83$ & \\
\hline 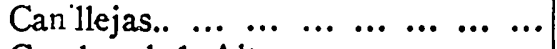 & Alcalá de Henares.. ... & 4.649 & 6.000 & $347 \cdot 791,52$ & \\
\hline Carabanchel Alto $\ldots$ & Getafe. ... $\ldots . . . . . . .$. & 7.660 & 7.000 & $397.688,85$ & \\
\hline $\begin{array}{cccccccc}\text { Carabaña... } & \ldots & \ldots & \ldots & \ldots & \ldots & \ldots & \ldots\end{array}$ & Ohindhón.. & 2.494 & $5 \cdot 500$ & $80.209,82$ & \\
\hline $\begin{array}{llllllll}\text { Cenicientos } & \ldots & \ldots & \ldots & \ldots & \ldots & \ldots & \ldots\end{array}$ & San Martín de la V. ... & 3.143 & $5 \cdot 500$ & I25.010,34 & \\
\hline $\begin{array}{lllllllll}\text { Cercedilla.. } & \ldots & \ldots & \ldots & \ldots & \ldots & \ldots & \ldots\end{array}$ & San Lorenzo del E. ... & 2.425 & $5 \cdot 500$ & $333.809,78$ & \\
\hline 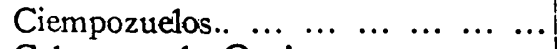 & Getafe. ... $\ldots . . . . . . .$. & $5 \cdot 300$ & 6.000 & $264 \cdot 512,32$ & \\
\hline Colmenar de Oreja... $\ldots \ldots \ldots \ldots$ & 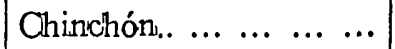 & 6.042 & 7.000 & $298.063,85$ & \\
\hline Collado-Villalba... $\ldots \ldots \ldots \ldots \ldots$ & San Larenzo del E. ... & 2.785 & $5 \cdot 500$ & I $32.050,55$ & \\
\hline $\begin{array}{llllllllll}\text { Chinchón } . . & \ldots & \ldots & \ldots & \ldots & \ldots & \ldots & \ldots\end{array}$ & Chindhón.. & 4.899 & 6.000 & $397.000,00$ & \\
\hline 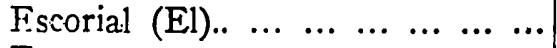 & San Lorenzo del E. ... & 2.773 & $5 \cdot 500$ & I37.000,00 & \\
\hline $\begin{array}{llllllll}\text { Estremera } & \ldots & \ldots & \ldots & \ldots & \ldots & \ldots & \ldots\end{array}$ & Chinchón.. $\ldots . . . .6$. & 2.134 & $5 \cdot 500$ & $56.758,56$ & \\
\hline $\begin{array}{llllllllll}\text { Getafe } & \ldots & \ldots & \ldots & \ldots & \ldots & \ldots & \ldots & \ldots\end{array}$ & Getafe $\ldots \ldots \ldots c c c \mid$ & $7 \cdot 373$ & 7.000 & 366.57 I,I I & \\
\hline $\begin{array}{lllllllll}\text { Leganés... } & \ldots & \ldots & \ldots & \ldots & \ldots & \ldots & \ldots\end{array}$ & Gretafe. ... $\ldots . . . .6 . .$. & 5.180 & 6.000 & $365.174,5^{8}$ & \\
\hline Morata de Tajuña... ... ....... & Chinuchón.. $\ldots . . . .6 . .$. & 3.802 & $5 \cdot 500$ & I9I.000,00 & \\
\hline $\begin{array}{lllllll}\text { Navalcarnero.. } & \ldots & \ldots & \ldots & \ldots & \ldots & \ldots\end{array}$ & Navalcarnero. .......... & 4.746 & 6.000 & $267.676,50$ & \\
\hline $\begin{array}{lllllllll}\text { Pinto } \ldots & \ldots & \ldots & \ldots & \ldots & \ldots & \ldots & \ldots & \ldots\end{array}$ & Getafe. $\ldots \ldots \ldots \ldots$ & $3 \cdot 347$ & $5 \cdot 500$ & $\mathrm{I} 37.879,52$ & \\
\hline Pozuelo de Alarcón.. ... ... ... ... & Navalcarnero. ... $\ldots . .$. & 2.537 & $5 \cdot 500$ & $209.088,58$ & \\
\hline San Lorenzo del Escorial... ... ... & San Lorenzo del E. ... & 5.753 & 6.000 & $770.000,00$ & \\
\hline San Martín de la Vega $\ldots \ldots \ldots$ & $\begin{array}{llllll}\text { Getafe. } & \ldots & \cdots & \cdots & \ldots & \cdots\end{array}$ & 2.736 & $5 \cdot 500$ & $190.000,00$ & \\
\hline San Martín de Valdeiglesias... ... & San Martín de lá V. ... & $4 \cdot 389$ & 6.000 & 3 I I.89I,00 & \\
\hline Torrejón de Ardoz... ... ... ... ... & Ailcalá de Henares.. ... & 2.770 & $5 \cdot 500$ & $95 \cdot 500,00$ & \\
\hline Torrelaguna... $\ldots \begin{array}{lllll} & \ldots & \ldots & \ldots & \ldots\end{array}$ & Torrelaguna.. $\ldots \ldots \ldots$ & 2.278 & $5 \cdot 500$ & I93.866,06 & \\
\hline $\begin{array}{lllllllll}\text { Valdemoro } & \ldots & \ldots & \ldots & \ldots & \ldots & \ldots & \ldots\end{array}$ & Getafe. $\ldots \ldots \ldots c c c \mid$ & $2.86 \mathrm{I}$ & $5 \cdot 500$ & $106.675,00$ & \\
\hline 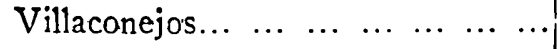 & 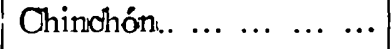 & 2.622 & $5 \cdot 500$ & $90.01 \mathrm{r}, 86$ & \\
\hline
\end{tabular}




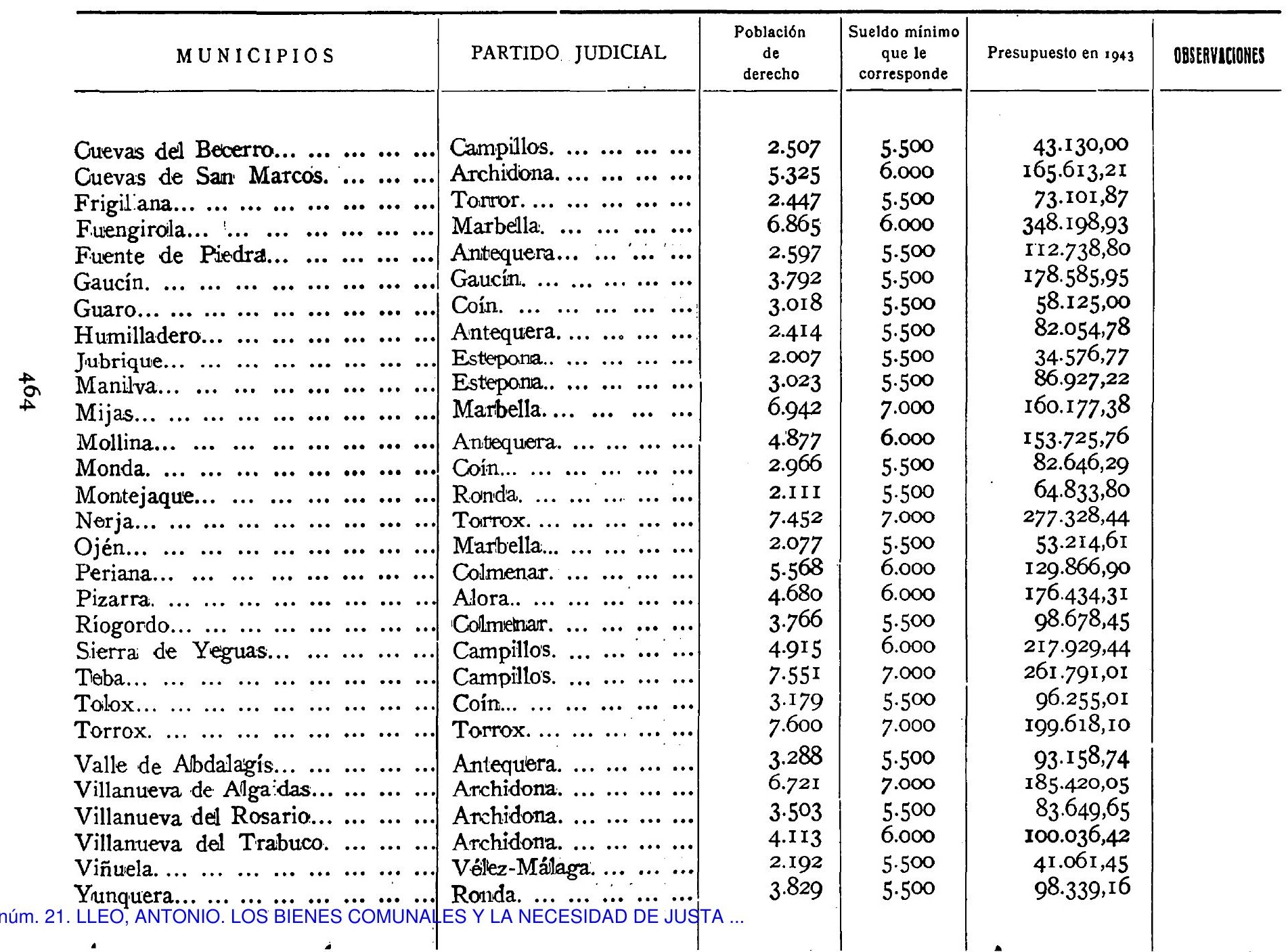


REVL-1945, núm. 21. LLEO, ANTONIO, LOS BIENES COMUNAIES Y LA NECESIDAD DE JUSTA ... PROVIN.CIA DE MURCIA

Abarán. ...

$\begin{array}{llllllll}\text { Alguazas... } & \ldots & \ldots & \ldots & \ldots & \ldots & \ldots & \ldots\end{array}$

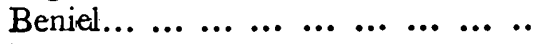

$\begin{array}{llllllll}\text { Blanca. ... } & \ldots & \ldots & \ldots & \ldots & \ldots & \ldots & \ldots\end{array}$

Cieza. $\ldots . . . . . . . .$.

$\begin{array}{llllll}\text { Mula. } & \ldots & \ldots & \ldots & \ldots & \ldots\end{array}$

$\begin{array}{lllll}\text { Murcia... } & \ldots & \ldots & \ldots & \ldots\end{array}$

Cieza. $\ldots \begin{array}{lllll} & \ldots & \ldots & \ldots & \ldots\end{array}$

$\begin{array}{llllllllllllllll}\text { Ceutí... } & \ldots & \ldots & \ldots & \ldots & \ldots & \ldots & \ldots & \ldots & \text { Mula. } & \ldots & \ldots & \ldots & \ldots & \ldots\end{array}$

$\begin{array}{llllllllllllll}\text { Fortuna... } & \ldots & \ldots & \ldots & \ldots & \ldots & \ldots & \ldots & \text { Cieza. } & \ldots & \ldots & \ldots & \ldots & \ldots\end{array}$

$\begin{array}{llllllllllllll}\text { Librilla. } & \ldots & \ldots & \ldots & \ldots & \ldots & \ldots & \ldots & \ldots & \text { Totana... } & \ldots & \ldots & \ldots & \ldots\end{array}$

$\begin{array}{lllllllllllllll}\text { Lorqui. } & \ldots & \ldots & \ldots & \ldots & \ldots & \ldots & \ldots & \ldots & \text { Mula. } & \ldots & \ldots & \ldots & \ldots & \ldots\end{array}$

$\begin{array}{llllllllllllllll}\text { Pliego... } & \ldots & \ldots & \ldots & \ldots & \ldots & \ldots & \ldots & \ldots & \text { Mula. } & \ldots & \ldots & \ldots & \ldots & \ldots\end{array}$

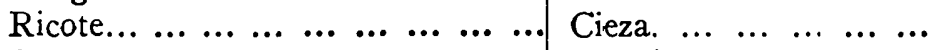

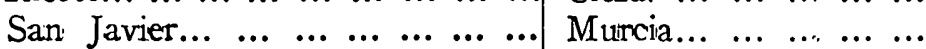

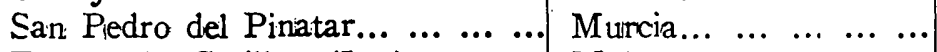

Torres de Cotillas (Las)... ... ...

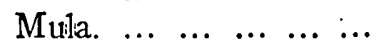

\section{PROVINCIA DE ORENSE}

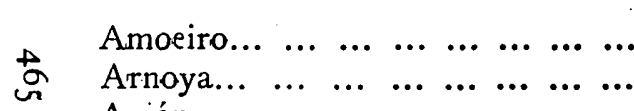

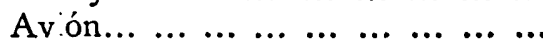

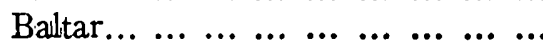

Bande..

Baños de Molgas.

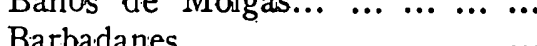

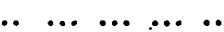

Barco $(\mathrm{El}) \ldots$

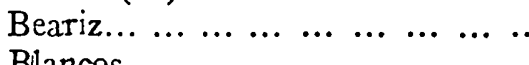

Blancos...

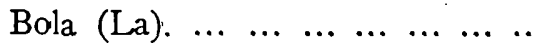

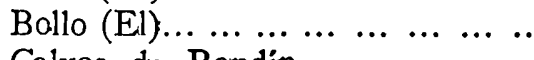

Calvos de Randín...

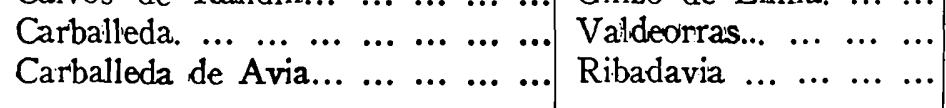

$\omega$

$\begin{array}{lllll}\text { Orense... } & \cdots & \cdots & \cdots & \cdots \\ \text { Ribardavia. } & \cdots & \cdots & \cdots & \cdots\end{array}$

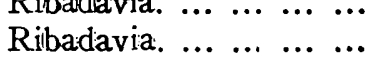

Ginzo de Limia. ... ...

Bandie. ... ... ... ........

$\begin{array}{llllll}\text { Allariz } & \ldots & \ldots & \ldots & \ldots & \ldots \\ & & \ldots\end{array}$

Orense ...

$\begin{array}{llll}\text { Valdeorras... } & . . & \ldots & \ldots\end{array}$

Carballino. ... ...

Ginzo de Limia. ... ...

Celanova. ...

Viana del Bollo. ... ...

Ginzo de Limia. ... ...

Valideorras... ...

$500.108,15$

4.183

5.109

4. 127

6.248

3.049

3.600

$2.69 \mathrm{I}$

2.929

6.652

4.377

4.806

6.000

7.000

$5 \cdot 500$

$5 \cdot 500$

$5 \cdot 500$

$5 \cdot 500$

7.000

6.000

6.000

I I $9.000,00$

$98.000,00$

$238.023,49$

I ro. I 49, I0

I95.0I 8,78

$94.862,99$

$106.400,00$

9I.32I, I 3

$86.920,82$

I67.980,6I

I $26.096,8 \mathrm{I}$

72.000,00

$5.68 \mathrm{I}$

2.455

6.434

4.239

6.463

6.318 


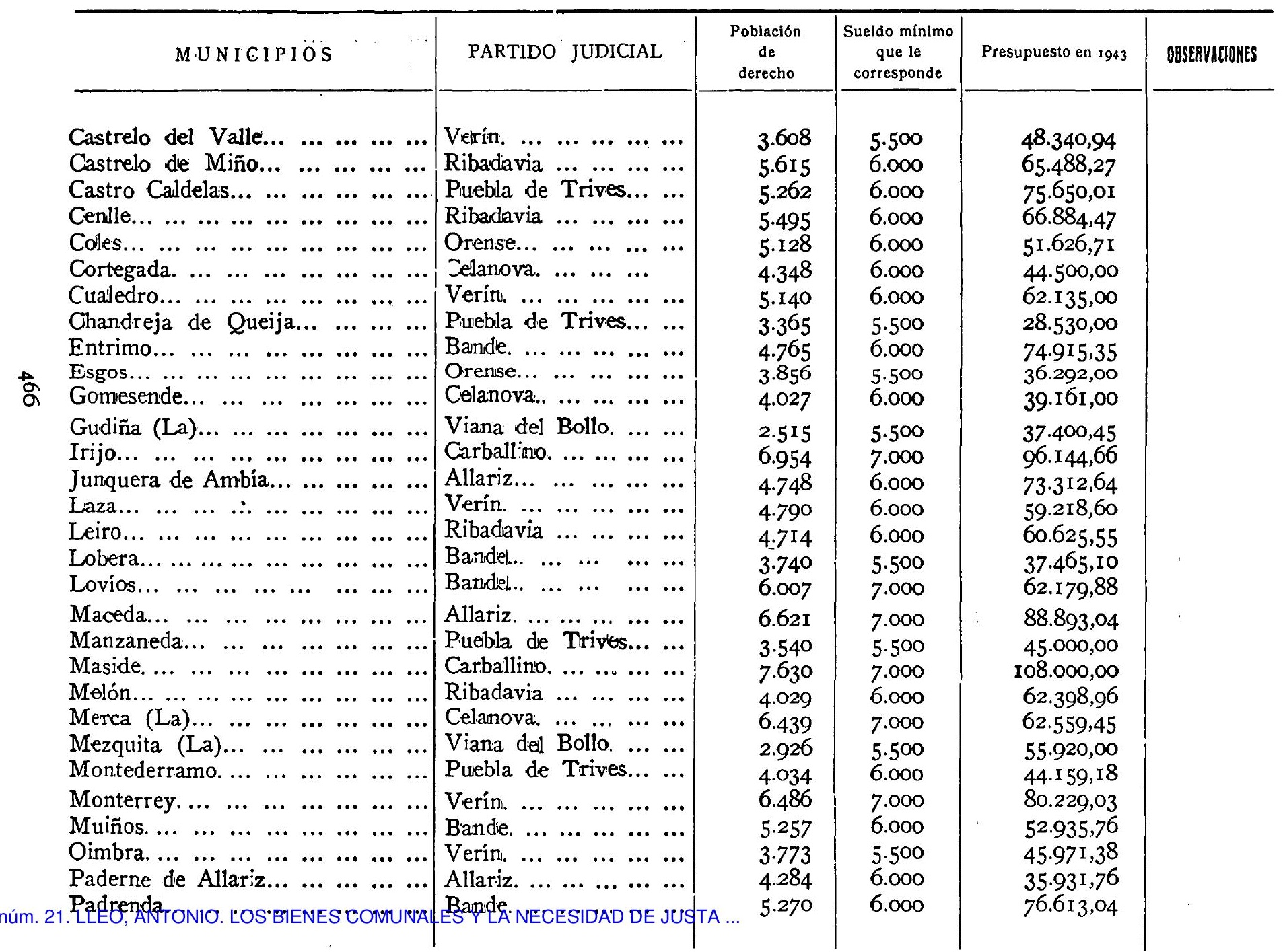


REVL-1945, núm. 21. LLEO, ANTONIO. LOS BIENES COMUNALES Y LA NECESIDAD DE JUSTA ...

Parada del Sil... ... ... ... ... ...

Pereiro de Aguiar... ... ... ... ...

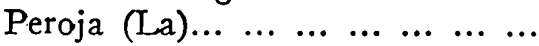

$\begin{array}{lllllllll}\text { Petin... } & \ldots & \ldots & \ldots & \ldots & \ldots & \ldots & \ldots & \ldots\end{array}$

$\begin{array}{lllllllll}\text { Piñor... } & \ldots & \ldots & \ldots & \ldots & \ldots & \ldots & \ldots & \ldots\end{array}$

Porquera... $\ldots \ldots \ldots \ldots \ldots$

Piuebla de Trivés... $\ldots \ldots \ldots \ldots$

$\begin{array}{lllllllll}\text { Pungin. } & \ldots & \ldots & \ldots & \ldots & \ldots & \ldots & \ldots & \ldots\end{array}$

Quintela de Leirado. ...

Rairiz de Veiga... $\ldots \ldots \ldots \ldots . . . . .$.

Ramiranes. ...

Ribadav:a...

Río.

Puebla de Trives... ... 3.516

Orense. ............ $\quad 7.370$

Orense. ............. $\quad 6.859$

Valdieiorras... $\ldots . . . .$.

3.I I 3

Valdino.

4.640

Ginzo de Limia. ... ... 3.447

Puebla de Trives... ... 6.662

Carballino. ...........

6.662
2.293

Cellanova. ...

Ginzo de Limia. ... ...

4.925

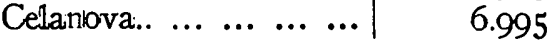

7.121

Ribadavia ..........

7.121
3.658

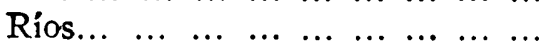

$\begin{array}{llllllllll}\text { Rúa. } & \ldots & \ldots & \ldots & \ldots & \ldots & \ldots & \ldots & \ldots & \ldots\end{array}$

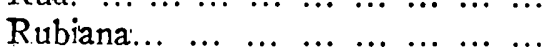

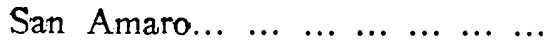

San Ciprián de Viñas... $\ldots . . . . .$.

San Cristóbal de Ceal... ... ... ...

\begin{tabular}{lllll} 
San Cristobal de Cea... & $\ldots$ & $\ldots$ & $\ldots$ \\
\hline
\end{tabular}

$\begin{array}{llllllll}\text { Sarreaus... } & \ldots & \ldots & \ldots & \ldots & \ldots & \ldots & \ldots\end{array}$

Taboadela.......................

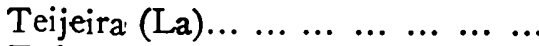

$\begin{array}{llllllllll}\text { Toén... } & \ldots & \ldots & \ldots & \ldots & \ldots & \ldots & \ldots & \ldots\end{array}$

Trasmiras... $\ldots \ldots \ldots \ldots \ldots$

$\begin{array}{llllllll}\text { Vega (La) } & \ldots & \ldots & \ldots & \ldots & \ldots & \ldots & .\end{array}$

$\begin{array}{lllllllll}\text { Verea... } & \ldots & \ldots & \ldots & \ldots & \ldots & \ldots & \ldots & \ldots\end{array}$

$\begin{array}{llllllll}\text { Villamarín. } & \ldots & \ldots & \ldots & \ldots & \ldots & \ldots & \ldots\end{array}$

Villamartín de Vaildeorras... ... ...

Villar de Barrio.

drives.....

$6.16 \mathrm{r}$

4.207

Valdeorras... $\ldots . . . . .$.

4.783

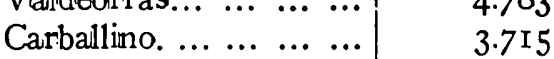

Orense. ... $\ldots . . . . . . . .4 \quad 4.160$

Carballino. ...........

4.160
6.688

Ginzo de Limia. ... ...

Ginzo de Limia. .......

Allariz.

3.236

4. 149

3.019

Pueblla del Trivies... ...

Orense. ............

Ginzo de Limia. ... ...

Valldeorras... $\ldots \ldots \ldots$

Bandie. ... ... ... ... ...

Orense...

2.352

4.429

3.832

$6.8 \mathrm{I} 2$

4.388

Valdeorras... ... ... ...

4.077

4.701

4. I 49

Villardevós.

Allariz. ...

Villarino die Conso.

Viana del Bollo.

6.340

2.508 


\begin{tabular}{|c|c|c|c|c|c|}
\hline M U N I CIPIOS & PARTIDO JUDICIAL & $\begin{array}{c}\text { Población } \\
\text { de } \\
\text { derecho }\end{array}$ & $\begin{array}{c}\text { Sueldo minimo } \\
\text { que le } \\
\text { corresponde }\end{array}$ & Presupuesto en 1943 & OBSERVACMOHES \\
\hline \multicolumn{6}{|l|}{ PROVINCIA DE OVIEDO } \\
\hline Amieva. $\ldots \ldots \ldots \ldots$ & Cangras de Onis ...... & 2.703 & $5 \cdot 500$ & $28.939,6 \mathrm{r}$ & \\
\hline $\begin{array}{lllllllll}\text { Bimenes... } & \ldots & \ldots & \ldots & \ldots & \ldots & \ldots & \ldots\end{array}$ & 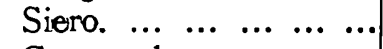 & $4 \cdot 378$ & 6.000 & $92.840,23$ & \\
\hline $\begin{array}{ccccccccc}\text { Boall... } & \ldots & \ldots & \ldots & \ldots & \ldots & \ldots & \ldots & \ldots\end{array}$ & Castropol. $\ldots . . . . \quad \ldots .$. & 7.493 & 7.000 & I I $3 \cdot 309$, I 2 & \\
\hline $\begin{array}{lllllllll}\text { Cabralles... } & \ldots & \ldots & \ldots & \ldots & \ldots & \ldots & \ldots\end{array}$ & Llanes. ... $\ldots . . . . . . . .$. & 5.236 & 6.000 & $67.288,5 \mathrm{I}$ & \\
\hline Cabranes... $\ldots \ldots \ldots \ldots$ & Infiesto... $\ldots \ldots \ldots \ldots$ & 3.931 & $5 \cdot 500$ & $75.76 \mathrm{r}, 45$ & \\
\hline 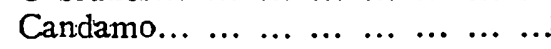 & Pravia. ... $\ldots \ldots \ldots \ldots$ & 5.087 & 6.000 & r $27.657,6 \mathrm{r}$ & \\
\hline $\begin{array}{ccccccccc}\text { Caso... } & \ldots & \ldots & \ldots & \ldots & \ldots & \ldots & \ldots & \ldots\end{array}$ & $\begin{array}{llllll}\text { Laviana... } & \ldots & \ldots & \ldots & \ldots\end{array}$ & 5.843 & 6.000 & I $53 \cdot 168,39$ & \\
\hline Castrillón... $\ldots \ldots \ldots \ldots \ldots$ & 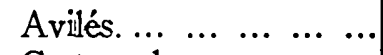 & 7.852 & 7.000 & $237.490,26$ & \\
\hline Castropol... $\ldots \ldots \ldots \ldots \ldots$ & Castropol. $\ldots \begin{array}{llll} & \ldots & \ldots & \ldots\end{array}$ & 6.795 & 7.000 & $99.999,50$ & \\
\hline 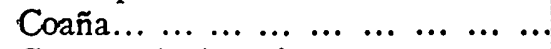 & Castropol. $\ldots \ldots \ldots c . .$. & $5.6 \mathrm{IO}$ & 6.000 & $51.256,76$ & \\
\hline Corvera de Asturias... ... $\ldots \ldots \ldots$ & Avilés $\ldots \ldots c c c c c$ & $4 \cdot 397$ & 6.000 & $62.742,63$ & \\
\hline 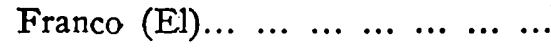 & Castropol $\ldots \ldots \ldots c c$ & 6.036 & 7.000 & $76.982,25$ & \\
\hline Grandas de Salime... ... ... ... & Castropoll $\ldots \begin{array}{llll} & \ldots & \ldots & \ldots\end{array}$ & $3 \cdot 590$ & $5 \cdot 500$ & $45 \cdot 527,22$ & \\
\hline $\begin{array}{llllllll}\text { Ibias } \ldots & \ldots & \ldots & \ldots & \ldots & \ldots & \ldots & \ldots\end{array}$ & Cangas de Naroel... ... & 6.765 & 7.000 & $93.000,00$ & \\
\hline $\begin{array}{llllllll}\text { Mlas... } & \ldots & \ldots & \ldots & \ldots & \ldots & \ldots & \ldots\end{array}$ & 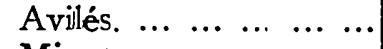 & 2.099 & $5 \cdot 500$ & $26.013,07$ & \\
\hline $\begin{array}{llllllll}\text { Morcin. } \ldots & \ldots & \ldots & \ldots & \ldots & \ldots & \ldots\end{array}$ & $\begin{array}{lllll}\text { Mieress... } & \ldots & \ldots & \ldots & \ldots\end{array}$ & 3.538 & $5 \cdot 500$ & $74.249,59$ & \\
\hline Muros de Nailón. ... ... ... ... & Pravia. ... $\ldots \ldots \ldots \ldots$ & 3.630 & $5 \cdot 500$ & I7 $1.000,00$ & \\
\hline $\begin{array}{llllllllll} & \text { Nava... } & \ldots & \ldots & \ldots & \ldots & \ldots & \ldots & \ldots & \ldots\end{array}$ & Infiesto. .............. & 6.561 & 7.000 & $177 \cdot 384,56$ & \\
\hline $\begin{array}{llllllll}\text { Noreña. } \ldots & \ldots & \ldots & \ldots & \ldots & \ldots & \ldots & \ldots\end{array}$ & Sivera... $\ldots \ldots \ldots \ldots \ldots$ & 2.562 & $5 \cdot 500$ & $262.270,00$ & \\
\hline $\begin{array}{llllllll}\text { Onís... } & \ldots & \ldots & \ldots & \ldots & \ldots & \ldots & \ldots\end{array}$ & Cangas de Onís. ... ... & 2.338 & $5 \cdot 500$ & $55 \cdot \mathrm{I} 78,25$ & \\
\hline Peñamellera Alta. $\ldots \ldots \ldots \ldots$ & Ldanes. ... $\ldots \ldots \ldots \ldots$ & 2.273 & $5 \cdot 500$ & $30.495,00$ & \\
\hline Peñamellera Baja.... ... ... ... & 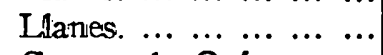 & 3.756 & $5 \cdot 500$ & $58.654,72$ & \\
\hline $\begin{array}{llllllll}\text { Ponga. } & \ldots & \ldots & \ldots & \ldots & \ldots & \ldots & \ldots\end{array}$ & Cangas ide Onís $\ldots \ldots$ & 3.158 & $5 \cdot 500$ & $43.485,16$ & \\
\hline $\begin{array}{llllllll}\text { Proaza. } & \ldots & \ldots & \ldots & \ldots & \ldots & \ldots & \ldots\end{array}$ & Ov:edio. ............ & $3.42 \mathrm{I}$ & $5 \cdot 500$ & $82.432,26$ & \\
\hline 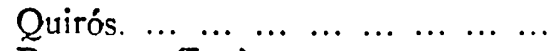 & 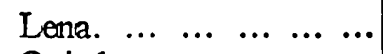 & $5 \cdot 530$ & 6.000 & I63. 580,58 & , \\
\hline Regueras $($ Las) $\ldots \ldots \ldots \ldots \ldots$ & Ov:edo. $\ldots \ldots \ldots \ldots \ldots$ & $4.53 \mathrm{I}$ & 6.000 & $45.765,65$ & \\
\hline 2R RibetedANATONIO.-LOS BIENES COML & ALdimeS.A.NEGESABAD.DE.J| & STA ... $3.27 \mathrm{I}$ & $5 \cdot 500$ & $57.934,02$ & \\
\hline
\end{tabular}




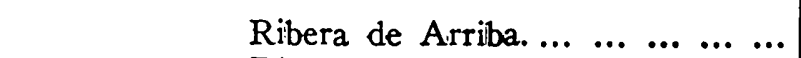

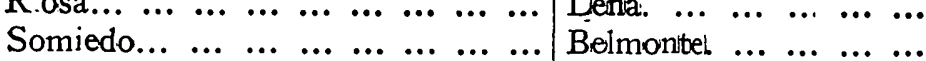

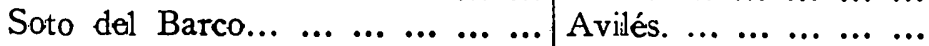

Tapia de Casariego...

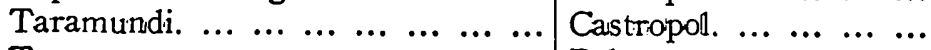

$\begin{array}{lllllllllllllll}\text { Teverga... } & \ldots & \ldots & \ldots & \ldots & \ldots & \ldots & \ldots & \text { Belmonte. } & \ldots & \ldots & \ldots & \ldots & \ldots\end{array}$

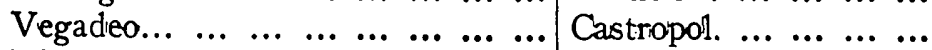

\begin{tabular}{lllllll|llllll} 
Villayón... & $\ldots$ & $\ldots$ & $\ldots$ & $\ldots$ & $\ldots$ & $\ldots$ & $\ldots$ & Luarca... & $\ldots$ & $\ldots$ & $\ldots$ & $\ldots$
\end{tabular}

\section{PROVINCIA DE PALENCIA}

Aguilar de Campoó... ... .........

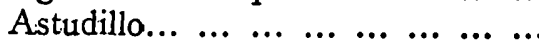

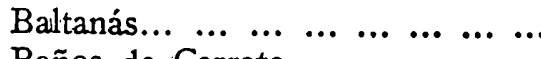

Baños de Cerrato. ... ............

Becerril de Campos... .... ... .......

Carrión de los Condes... ..........

$\begin{array}{llllllll}\text { Dueñas. ... } & \ldots & \ldots & \ldots & \ldots & \ldots & \ldots & \ldots\end{array}$

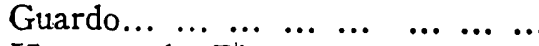

今े Herrera del Pisulerga...

Paredes de Nava. ... .............

Pomar de Valdivia...

\begin{tabular}{lllllllll} 
Saldaña... & $\ldots$ & $\ldots$ & $\ldots$ & $\ldots$ & $\ldots$ & $\ldots$ & $\ldots$ \\
\hline
\end{tabular}

Santibáñez de da Peña... $\ldots . . . . . .$.

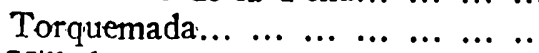

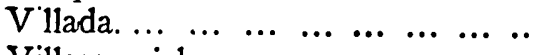

\begin{tabular}{llllllll} 
Villarramiel... & $\ldots$ & $\ldots$ & $\ldots$ & $\ldots$ & $\ldots$ & $\ldots$ & $\ldots$ \\
\hline
\end{tabular}

Cervera del Pisuerga...

Astudillo. ...

$\begin{array}{lllll}\text { Balltanás.. } & . . & \ldots & \ldots & \ldots \\ \end{array}$

Palencia... ... ... ... ...

Pallencia... ... ... ... ...

Carrión de los Condes.

Palencia... ... ... ... ...

Cervera del Pisuerga...

Salldaña...

Frechilla. ... ... ... ...

Cervera del Pisuerga...

Saildaña..

Cervera del Pisuerga...

Astudillo.

$\begin{array}{lllll}\text { Fretchilla. } & . . & \ldots & \ldots & \ldots \\ & \ldots & \ldots\end{array}$

PROVINCIA DE LAS PALMAS

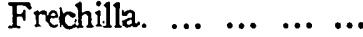

Guía de Gran Canaria.

Agaete... Telde.

Agruimes.

..




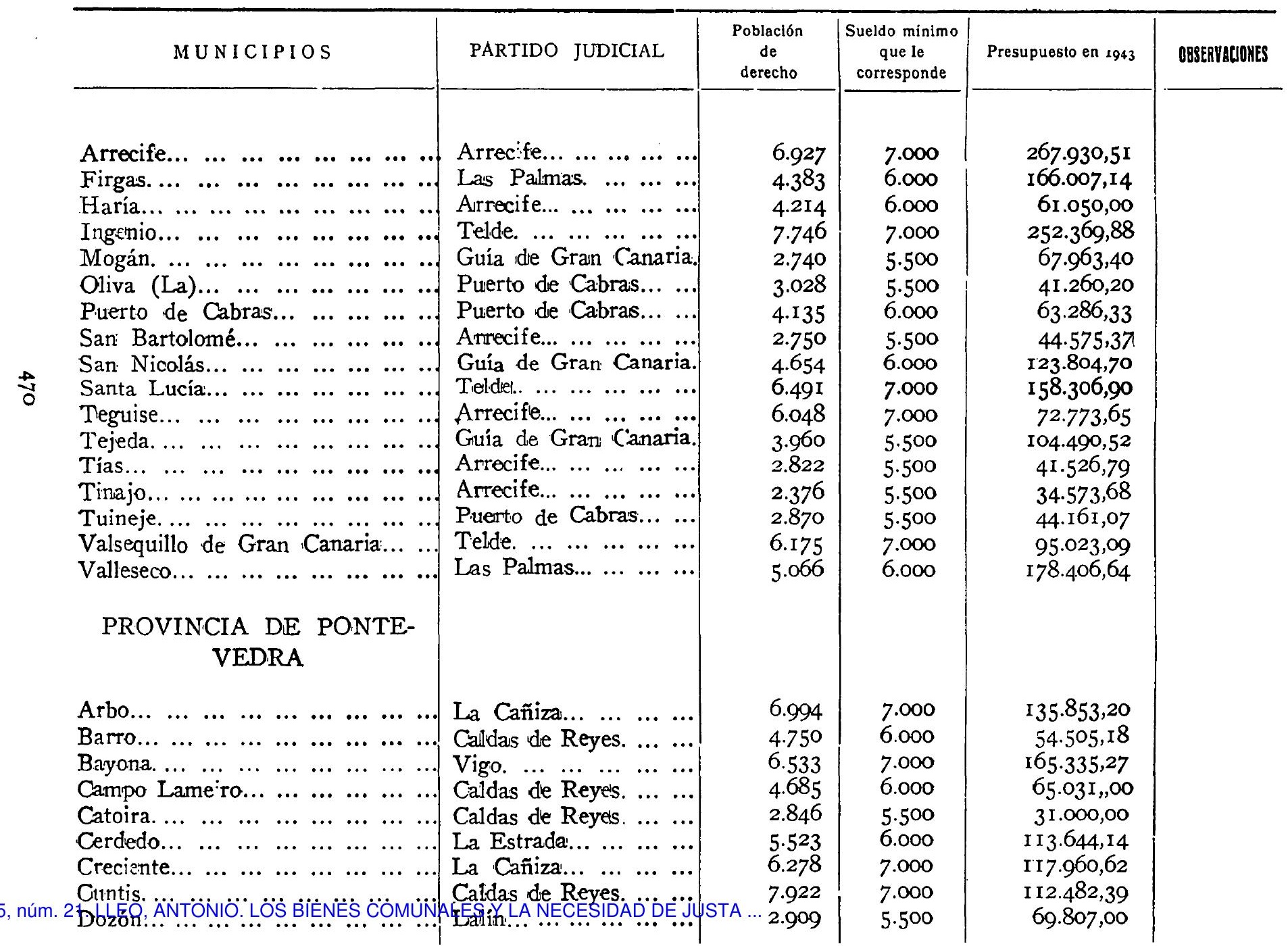


$\begin{array}{lllllllll}\text { Geve... } & \ldots & \ldots & \ldots & \ldots & \ldots & \ldots & \ldots & \ldots\end{array}$

$\begin{array}{llllllll}\text { Golada. } & \ldots & \ldots & \ldots & \ldots & \ldots & \ldots & \ldots\end{array}$

$\begin{array}{llllllll}\text { Grove. } & \ldots & \ldots & \ldots & \ldots & \ldots & \ldots & \ldots\end{array}$

$\begin{array}{llllllllll} & \operatorname{Lama} . . . & \ldots & \ldots & \ldots & \ldots & \ldots & \ldots & . . & . .\end{array}$

Meaño.

Meis...

Moraña...

Oyа...

Pazos de Borbén.

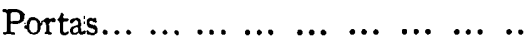

Ployo...

Puentecesures

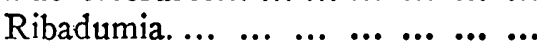

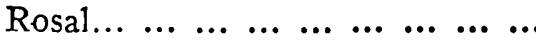

Salceda de Caselas...

$\begin{array}{llllllll}\text { Sotomayor. ... } & \ldots & \ldots & \ldots & . . & \ldots & . . & . .\end{array}$

$\begin{array}{lllllllll} & \text { Valga... } & \ldots & \ldots & \ldots & \ldots & \ldots & \ldots & \ldots\end{array}$

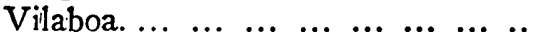

$\pm$

Villanueva de Arosa.... ... ... ...

PROVINCIA DE SALAMANCA

Alba de Tormes... ... $\ldots \ldots \ldots \ldots$ Aldeadávila de la Ribera... .... ... Cantalapiedra..

Cantalpino...

Fuente de San Esteban ( $\mathrm{La}$ )...

Furenteguinaldo...

Gu' juelo.

Hinojosa de Duero

Ledesma..

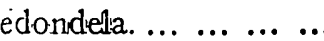

$\begin{array}{lllll}\text { Pontevedra... } & \ldots & \ldots & \ldots\end{array}$

Ladín...

Cambados. ... ... ... ...

Puvente-Caldelas.

Cambadas. ... ... ... ...

Cambados. ..............

Caldas de Reyes. ... ...

Túy..

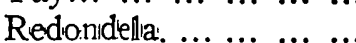

Caldas de Reyes. ... ...

Pontevedra...

Caldas de Reyes. ... ...

Cambadios. ... ..........

$\begin{array}{llllllll}\text { Túy } & \ldots & \ldots & \ldots & \ldots & \ldots & \ldots & \ldots\end{array}$

Túy $\ldots \ldots \ldots \ldots$

Redondela. ... ... ... ...

Calldas de Reyes.

Pontevedra... ... ... ...

Cambados. ... ..........

Alba de Tormes. ... ...

$\begin{array}{lllll} & \text { Vitigudino... } & . . & \ldots & \ldots\end{array}$

Peñaranda de B. ... ...

Peñaranda de B. ... ...

Ciudad-Rodr'go.

Ciudad-Rodr:go.

Aliba de Tormes. .......

Vitigudino... ... ...

Ledesma.
$65.170,23$ 49.163,74 $90.732,24$ I $82.356,70$ ro5.193,65 91.168,32 $85.000,00$ 205.000,00 $44.052,04$ $80.000,00$ $50.454,55$ I $38.942,89$ $58.975,37$ $54.300,89$ I $27.583,18$ $70.000,00$ $59.889,22$ $77.237,38$ $67.648,42$ I $27.909,89$

233.438 , 10 $70.838,93$ $80.416,39$ $77 \cdot 308,25$ 79. I 57,00 I 39.499 , I 7 2 $3.723,55$ I6I. 343,49 I6r. 343,49 


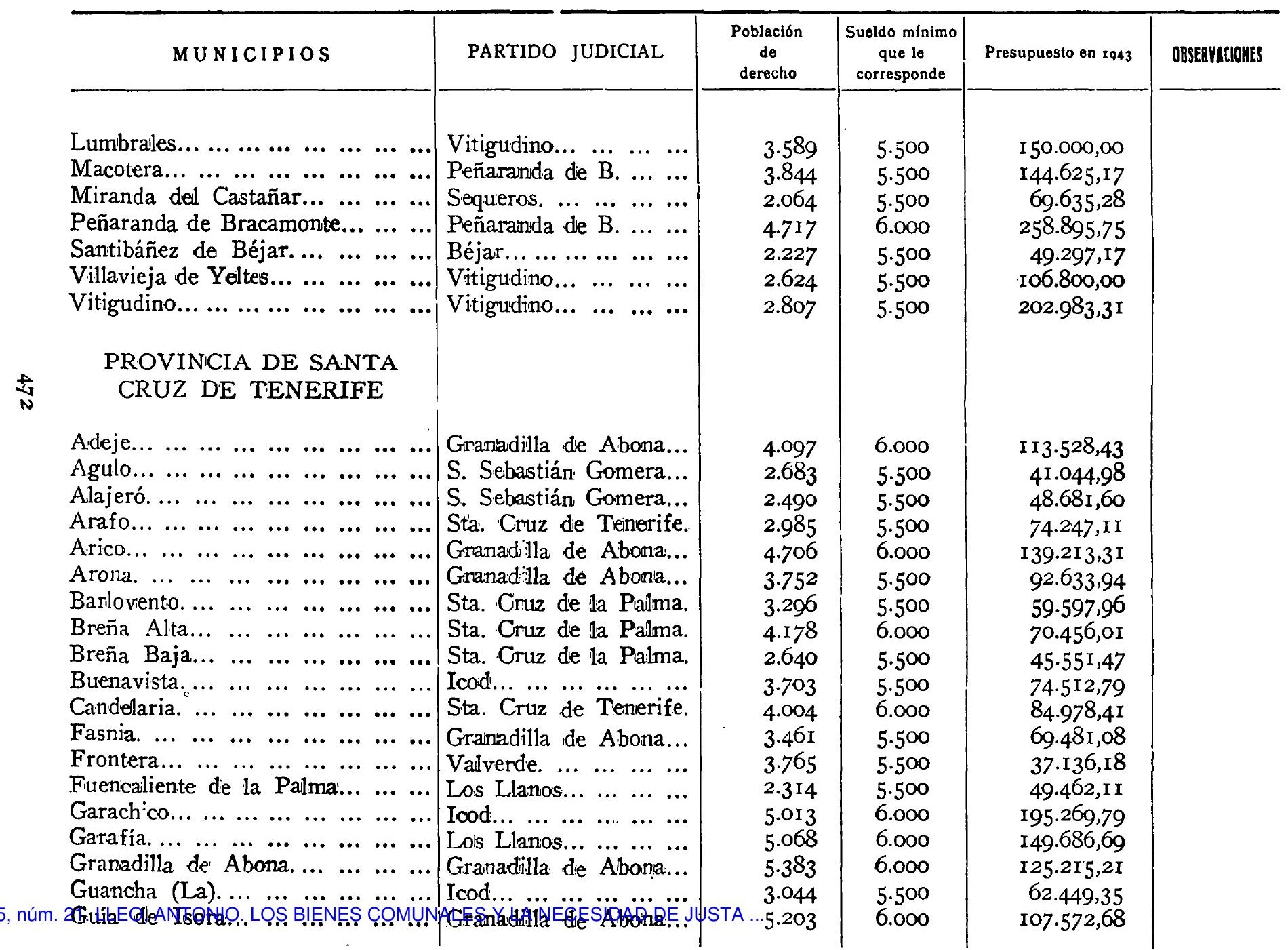


Hermigua ${ }^{2}$ NTIO: LOS BIENES COMUN S SlebastiámGGomera

Llanos. (Los). ... ... ............ Matanza de Acentejo (La). ... ... Mazo. ... ... Paso (El)...

$\begin{array}{lllllll}\text { Puntagorda } \ldots & \ldots & \ldots & \ldots & \ldots & \ldots & \ldots\end{array}$

Reallejo Bajo. ... $\ldots \ldots \ldots \ldots . . .$.

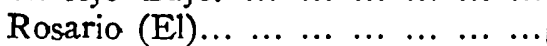

San Andrés y Sauces... ... ... ...

San Juan de la Rambla.... ... ...

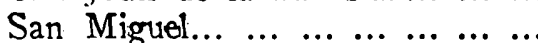

San Sebastián de la Gomera... ...

Santa Ursula... .................

Santiago dell Teide...

$\begin{array}{lllllllll}\text { Saruzal } . . . & \ldots & \ldots & \ldots & \ldots & \ldots & \ldots & \ldots & \ldots\end{array}$

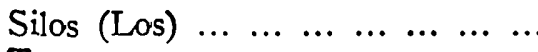

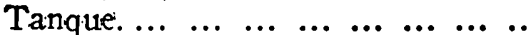

$\begin{array}{llllllll}\text { Tazacorte... } & \ldots & \ldots & \ldots & \ldots & \ldots & \ldots & \ldots\end{array}$

Tegueste... $\ldots \ldots \ldots \ldots \ldots$

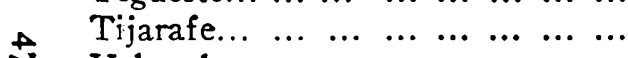

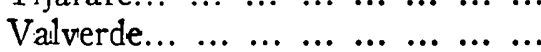

Valle Gran Rey... ... ... ... ... ...

Vallehermoso. ...

Victoria de Acentejo (La)... ... $\ldots$

La Laguna... ... ......

I $50.000,00$ Sta. Cruz de la Palma. Los Llanos... ......... Los Llanios... ......... La Oratava. ... $\ldots . .$. La Laguna... ... ...... Sta. Cruz de la Palma. La Orotava. ... ....... Granadilla de Aibona... S. Sisbastián Gomera... La Laguna... ... ... ...

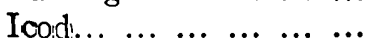
La Laguna... $\ldots \ldots \ldots$ Icod... $\ldots \ldots \ldots \ldots$ Icod $\ldots \ldots \ldots$ Ios Llanos... $\ldots \ldots \ldots$ La Laguna... ... ... ... Los Llanos... ... ... ... Valvende. S. Sebastián Gomera... S. Sebastián Gomera... La Laguna... ... ... ...

I I $4.359,7$ I I68.645,40

\section{PROVINICIA DE SANTANDER}

Alfoz de Lloredo... ... .........

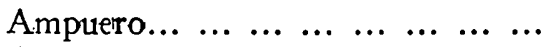

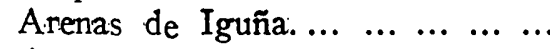

$\begin{array}{llllllll}\text { Arnuero... } & \ldots & \ldots & \ldots & \ldots & \ldots & \ldots & \ldots\end{array}$

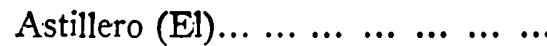

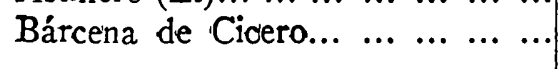

Torrelavega. $\ldots \ldots \ldots$

$\begin{array}{lllll}\text { Lanedo... } & \ldots & \ldots & \ldots & \ldots\end{array}$ 


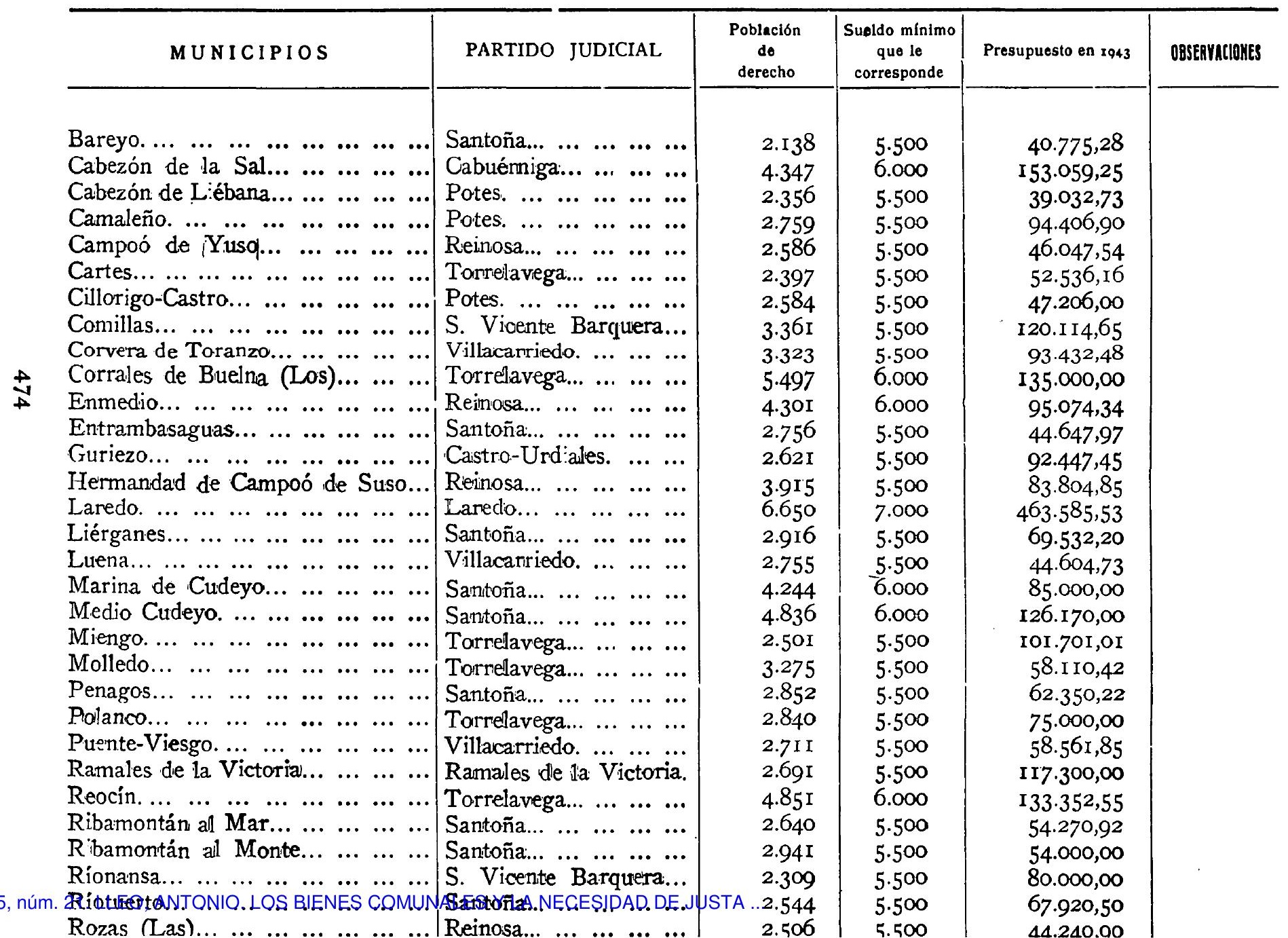


REVL-1945. núm. 21. RuesgantonIO. LOS BIENES COMUNAU Ramalles de da Victorja

San Felices de Buelna... ..........

Santa Cruz de Bezana... ... ... ...

Santa María de Cayón... ... ... ...

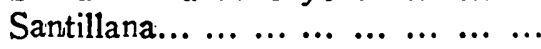

Santiurde de Toranzo... ........

San Vicente' de la Barquera... ...

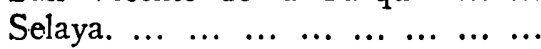

$\begin{array}{llllllllll}\text { Soba... } & \ldots & \ldots & \ldots & \ldots & \ldots & \ldots & \ldots & \ldots\end{array}$

$\begin{array}{llllllll}\text { Suances... } & \ldots & \ldots & \ldots & \ldots & \ldots & \ldots & \ldots\end{array}$

\begin{tabular}{llllllll} 
Valdáliga... & $\ldots$ & $\ldots$ & $\ldots$ & $\ldots$ & $\ldots$ & $\ldots$ & $\ldots$ \\
\hline
\end{tabular}

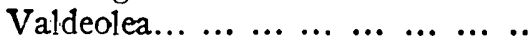

Valdeprado del Río.

Valderredible.

orretavega... .........

Santander. ... ........

Villacarriedo. .........

Tonrelavega... ... ......

Villacarriedo. ... ......

S. Vicente Barquera...

Villacarriedo. .........

Ramalles del la Victoria.

Tornelavega... ... .......

S. Vicente Barquera...

Reinosa... ... ... ... ...

Reinosa... $\ldots . . . . . . .$.

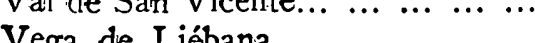

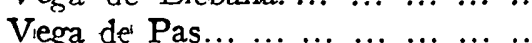

$\begin{array}{llllllll} & \text { Villacarriedo... } & \ldots & \ldots & \ldots & \ldots & \ldots & \ldots\end{array}$

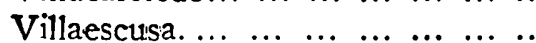

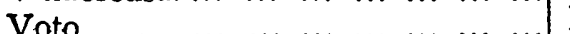

Reinosa... $\ldots . . . . . . . .$.

S. Vicente Barquera..

Plotes... ............

Villacarriedo. .........

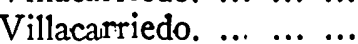

Santander $\ldots . . .6 . .$.

Laredo... $\ldots . . . . . . .$.

\section{PROVINCIA DE SEGOVIA}

Cantaliejo.

Carbonero el Mayor. ...

Cuéllar.

Sepúllveida... $\quad \ldots \quad \ldots \quad \ldots$

Segovia... ..........

Cuéllar... $\ldots . . . . \quad \ldots .$.

Espinar (El)...

Segovia..

Santa María la Real...

Nava de la Asunción..

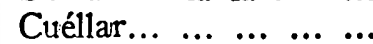

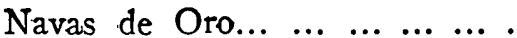

San Ildefenso o La Granja... ...

Segovia...

PROVINCIA DE SEVILLA

Aguadulce..

Estepa. ... ... ... ... ...

Alanís.

Cazalla de la Sierra.

2.903

2.705

$3.12 \mathrm{I}$

2.I32

4.394

3.595

4,203

4.332

2.362

6.925

3.268

2.507

2.093

2.884

3.418

4.097

3.742

2.783

7.312

3.744

2.465

2.066

3.438

$5 \cdot 500$

5.500

7.000

5.500

5.500

5.500

$5 \cdot 500$

3.770

5.500

6.000
$49.260,00$ 5I.396,82

I I $0.099,24$

r $51.572,18$

$60.919,66$

68.501,54

$83.707,44$

7 I.3OI, 24

$57.959,7 \mathrm{I}$

$92.789,64$

$63.716,18$

78.619,9I

$57,532,26$

I 43. . 32,38

$56.647,39$

$69.939,01$

I I0.021,79

$70.963,55$

$67.676,7 \mathrm{I}$

$61.509,33$

$200.000,00$

$352.500,00$ 499.999,00

I. $075 \cdot 545, \mathrm{I} \mathrm{I}$

I67.763,80

373.296 .30

$233.848,03$

233.554,99 I 8 I. 975,57 


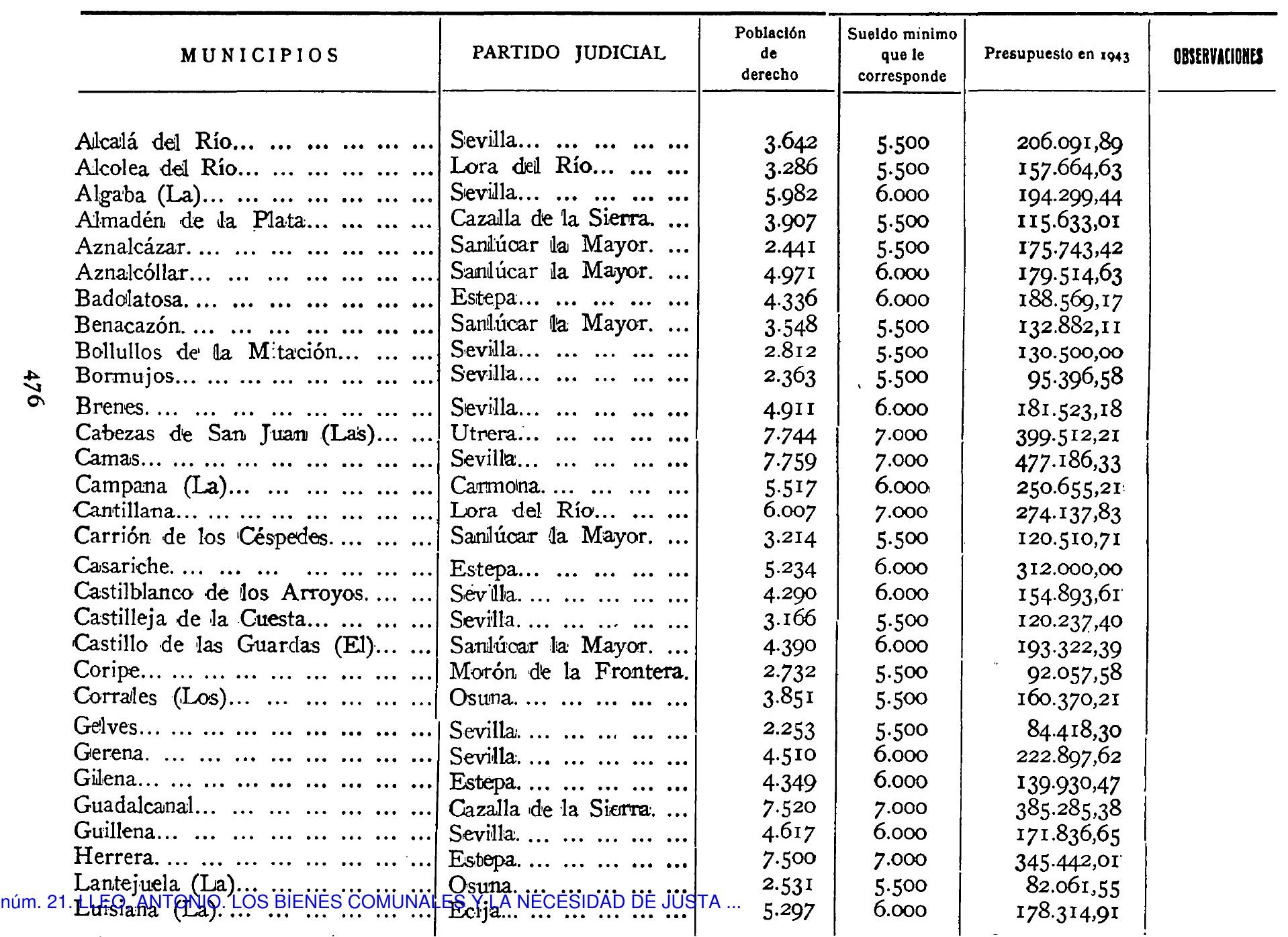




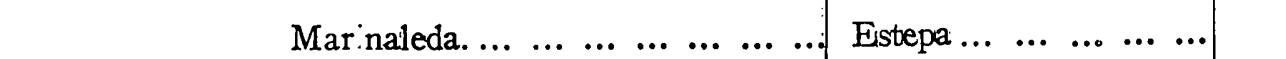
Martín de la Jara...

Osuna

Molares (Los).

Utrera ...

Navas de la Comoepcion

Navas de la Conoepción (Las).

Cazalla de la Sierra

Olivares... ...

Estepa

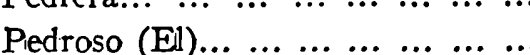

$\begin{array}{llllllll}\text { Peñafior... } & \ldots & \ldots & \ldots & \ldots & \ldots & \ldots & \ldots\end{array}$

Cazalla de la Sierra

Lora diel' Río

2.280

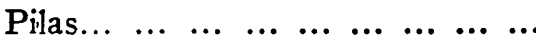

Pruna... ... ................

Puebla de los Infantes (La)...

6.191

6.000

5.500

$5 \cdot 305$

7.000

Morón Frontera

6.000

5.275

Puebla del Río (La).... ... ... ...

Real de la Jara (El)... ... ... ..

Rinconada (La)...

Roda de Andalucia (La)... ... ...

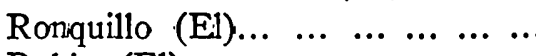

$\begin{array}{lllllll}\text { Rubio (El).. } & \ldots & \ldots & \ldots & \ldots & \ldots & . .\end{array}$

$\begin{array}{lllllll}\text { Salteras... } & \ldots & \ldots & \ldots & \ldots & \ldots & \ldots\end{array}$

Lora diel Río ... ......

6.000

$\begin{array}{lllll} & & & & \\ & & & \end{array}$

3.332

la la Sierra

6.000

5.965

$5 \cdot 500$

Servilla ...

6.000

5.202

Sanlúcar la Mayor..

2.I I 3

Osuna

6.533

Sanlúcar la Mayor..

2.020

5.500

San Juan de Aznalfarache... ... ...

Sevilla ...

4.684

Sanlúcar la Mayor.

$\begin{array}{llllll}\text { Sanlúcar la } \text { Mayor... } & \ldots & \ldots & \ldots & \ldots\end{array}$

$\begin{array}{lllllll}\text { Santiponce. ... } & \ldots & \ldots & \ldots & \ldots & \ldots & \ldots\end{array}$

$\begin{array}{llllllll}\text { Sauce jo }(E 1) & . . & \ldots & \ldots & \ldots & \ldots & \ldots & . .\end{array}$

$\begin{array}{llllllllll}\text { Tocina. } & . . & \ldots & \ldots & \ldots & \ldots & \ldots & \ldots & \ldots\end{array}$

$\begin{array}{lllllllll}\text { Tomares... } & \ldots & \ldots & \ldots & \ldots & \ldots & \ldots & \ldots\end{array}$

$\begin{array}{lllllllll}\text { Umbrete... } & \ldots & \ldots & \ldots & \ldots & \ldots & \ldots & \ldots\end{array}$

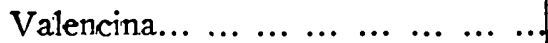

Villamanrique de la Condesa... ...

Villanueva del Ariscal... ... ...

V'llanueva de San Juan. ... ... ...

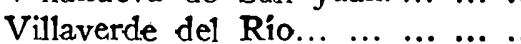

Selvilla ...

5.458

2.799

Osuna $\ldots \ldots \ldots c c c$

Lora dell Río ...

6.915

5.215

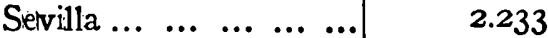

2.950

Sanlúcar la Mayor..

Sevilla ... ...

2.046

Sanlúcar la Mayor..

3.325

Sanlúcar la Mayor..

2.807

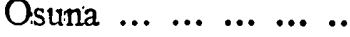

2.824

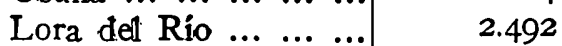

7.000

5.500

6.000

6.000

5.500

7.000

6.000

5.500

5.500

5.500

5.500

I I $3.095,38$

I 32. I 59,03

I 32. I 59,03

I4I.729, 54

I89.394,33

I $46.280,07$

230.460,33

I $42.134,25$

$350.891,85$

$279.929,89$

$204.876,85$

208.743,50

I $38.393,65$

$327.542,6 \mathrm{r}$

$286.015,76$

7I.I 48,62

293.193,66

I $57.023,75$

I I $7 \cdot 500,00$

305. I78, I 5

I $28.250,00$

283.553 , I9

I64.608,80

$75.000,00$

I $32.628,59$

I $52.211,96$

I $6.052,40$

$96.000,00$

$5.500 \quad 83.658,13$

I23.95I,74 


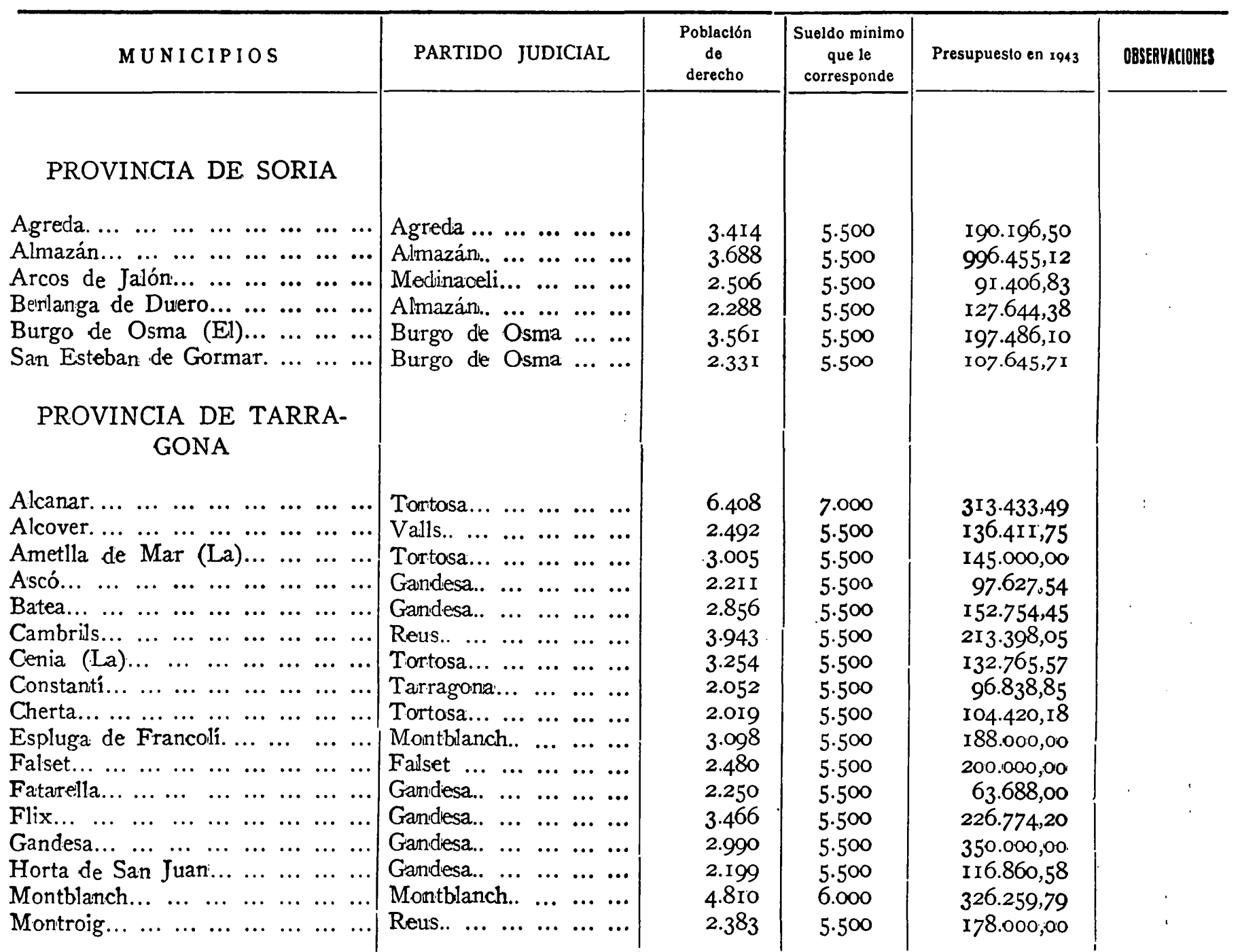

